\title{
Ceramic Fiber-Based Structures as Catalyst Supports: A Study on Mass and Heat Transport Behavior Applied to $\mathrm{CO}_{2}$ Methanation
}

\author{
Agustina Sánchez, Viviana G. Milt, Eduardo E. Miró, and Robert Güttel* \\ Cite This: https://dx.doi.org/10.1021/acs.iecr.0c01997 \\ Read Online
}

ABSTRACT: Fibrous structures present interesting characteristics as catalyst supports for heat- and mass-transfer-limited reactions. This paper investigates the mass and heat transport behavior of ceramic fiber-based catalysts (catalytic ceramic paper) by applying them to the exothermic reaction of $\mathrm{CO}_{2}$ methanation. Catalytic experiments were carried out to fit the activity of the catalysts with known kinetics. A fixed-bed reactor model was used to determine the efficiency and efficiency losses caused by different transport phenomena, as well as to perform a sensitivity study focused on heat transfer. The results show that heat transfer limitations are the main cause for losses in reactor efficiency, with steep temperature profiles developing inside the reactor. Poor heat transfer limits the development of highly

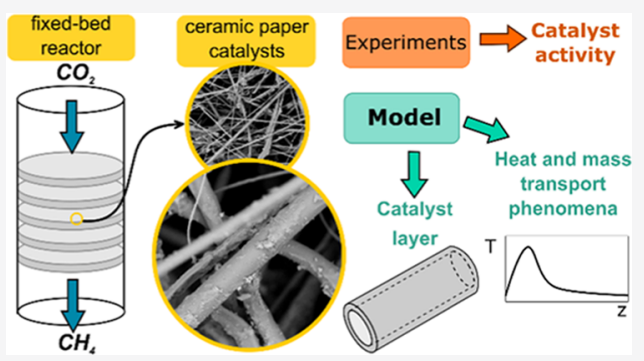
active catalysts, while pressure drop restricts the flow rate and therefore the productivity. The use of ceramic materials with higher thermal conductivity and increasing the fiber diameter are promising approaches to enhance heat transfer, reduce pressure drop, and improve overall reactor performance.

\section{INTRODUCTION}

The deposition of catalytically active materials on a substrate that gives structure to the catalytic system is a viable way to achieve technologically applicable arrangements, especially relevant for applications where pressure drop and heat and mass transport become important obstacles for chemical reactors. Molded pellet catalysts often present intraparticle diffusive limitations, which can cause strong reductions in observed reaction rates. ${ }^{1,2}$ Other complications that can arise from the use of packed beds of pellets are irregular flow distribution and poor temperature control. ${ }^{3-5}$

In structured catalysts, the geometry is fixed by design, in contrast with the random orientation of particles that results from dumping pellets into a column. The geometry can be optimized in several levels and scales because through the structuring, the different phenomena occurring inside the reactor bed (reaction, internal diffusion, heat and mass transfer, pressure drop) are decoupled, introducing new degrees of freedom and, thus, better control. ${ }^{6-8}$ This decoupling also gives structured catalysts the advantages of ease of scale-up and accurate description of the fluid mechanics. ${ }^{9}$

With the aim of structuring the active material in a suitable way, many substrates have been developed. One of the more widespread examples is monolithic honeycombs, where the catalyst is supported on each channel wall. ${ }^{10}$ Ceramic monoliths show very little pressure drop and high thermal resistance, but they are poorly suited for applications where radial heat transfer is needed. Metallic monoliths introduce improvements to the heat transfer to an extent, although the development of a catalytic coating on a metal surface is challenging. ${ }^{11}$ Another example is sponge-type structures, which are constituted by a tridimensional reticulate structure of connected cells and present elevated porosity (80-90\%). Ceramic and metallic sponge structures favor radial mixing, but they are mostly suited for reactions with short contact times and are rather costly to manufacture. ${ }^{12,13}$

Fiber-based structures made of different materials are among the most studied catalyst supports in recent years. Fibrous beds are alternatives with a lower manufacturing cost than sponges and microchannel reactors. ${ }^{14}$ Knitting, weaving, and wet-laying are the methods that can be used to produce fibrous structures with different configurations, which allow better control of flow patterns. The dimensions of the fibers are usually small, with typical diameters ranging from 10 to $1000 \mu \mathrm{m}$, which give these materials a high surface-to-volume ratio, directly influencing external mass and heat transfer. Since the catalytically active material is placed in the shape of a thin film or layer, the diffusion distances tend to be short, allowing for a better accessibility of the reactants to the active sites. ${ }^{15}$ These structures offer high void fractions as well (70-85\%), which is beneficial for a lower pressure drop through the bed. The tortuosity of the fibrous bed can improve the mixing of the fluid in the radial direction, which would be beneficial for temperature and flow uniformity. ${ }^{16}$

Received: April 20, 2020

Revised: August 17, 2020

Accepted: August 31, 2020

Published: August 31, 2020 
Recent works have reported the development of fibrous catalysts and catalytic supports for a variety of applications. Cuo et al. ${ }^{17}$ synthesized ceramic membranes from mullite fibers and high-temperature earth-abundant binders, with the aim of removing volatile organic compounds (VOCs) and retaining particulate material from diverse industrial sources at the same time. They observed good active material dispersion and enhanced contact of the gases to the active sites. Wang et al. ${ }^{18}$ prepared $\mathrm{NiAl}_{2} \mathrm{O}_{4}$ nanofibrous ceramics by electrospinning and grew a $\mathrm{Ni}$ nanocatalyst in situ. They demonstrated that the catalyst was very active for methane partial oxidation and resistant to deactivation by sintering, owing to the combined advantages of metal gauze catalysts and conventional supported nanocatalysts. Ma et al. ${ }^{19}$ studied the performance of a fibrous catalyst compared to an impregnated pellet catalyst for methane partial oxidation. They observed better dispersion of the active material, and their results suggested enhanced mass transfer for the fibrous material. Danaci et al. $^{20}$ and Middelkoop et al. $^{21}$ proposed threedimensional (3D)-printed catalysts with a fibrous geometry and a monolithic structure, as the development of new catalysts for $\mathrm{CO}_{2}$ methanation. This is a highly interesting technique since it allows many degrees of freedom in the design of materials tailored to specific applications.

Ceramic papers are an example of recently developed fibrous supports that have been studied in diesel soot filtration and combustion, $^{22} \mathrm{CO}$ combustion, $^{23}$ and ethane oxidative dehydrogenation ${ }^{24}$ among other applications. These structures are made of rather inexpensive fibrous material, following a papermaking technique, where the cellulosic fibers are partially replaced by ceramic ones, and a binder is added to keep the ceramic fibers attached at the contact points. ${ }^{25}$ Ceramic papers are flexible structures that have good mechanical stability and are easy to handle. They can be adapted to a number of different reactor geometries, by cutting and piling or molding the paper sheets. ${ }^{26}$ For example, Saimura et al. ${ }^{27}$ have published results on the advantages of an arrangement of two different ceramic paper catalysts piled in a single bed applied to sequential desulfurization and methane-steam reforming of simulated biogas containing hydrogen sulfide. Similarly, Ishihara et al. ${ }^{28}$ showed a sequential arrangement of catalytic ceramic papers and ceramic papers with a base, which enabled sequential reactions in one reactor, for SuzukiMiyaura cross-coupling reaction.

Although fibrous materials have been studied in numerous experimental studies, little is known about the mass and heat transfer characteristics of ceramic papers and other fibrous supports. In general, they seem to offer an interesting trade-off between mass transfer and pressure drop. ${ }^{14}$ However, correlations are only available for very few structures, mostly wire meshes and metallic fibers. ${ }^{29-31}$ Reichelt et al. have recently published a more comprehensive study where they generalize a correlation for a wide variety of fiber supports, ${ }^{32}$ allowing for a better basis of comparison between them. Besides wire meshes and foams (which can be considered similar to fibrous materials), ${ }^{33-35}$ not many studies deal with describing heat transfer properties of fiber beds.

Because of their high external surface areas and short diffusional distances, however, fiber-based catalysts most likely would be better utilized in applications that involve reaction systems with fast rates, which are usually mass- and heat transfer-limited. ${ }^{14,16,36}$ For this reason, diverse fibrous catalysts have been applied to fast reactions such as $\mathrm{N}_{2} \mathrm{O}$ decom- position $^{37}$ and $\mathrm{CO}$ and hydrocarbon oxidation. ${ }^{31,38,39}$ The hydrogenation of $\mathrm{CO}_{2}$ to generate $\mathrm{CH}_{4}\left(\mathrm{CO}_{2}\right.$ methanation) is an exothermic reaction of practical relevance that presents relatively fast rates ${ }^{40,41}$

$$
\begin{gathered}
\mathrm{CO}_{2}+4 \mathrm{H}_{2} \rightleftarrows \mathrm{CH}_{4}+2 \mathrm{H}_{2} \mathrm{O}_{(\mathrm{g})}, \\
\Delta H_{\mathrm{r}}(298 \mathrm{~K})=-165 \mathrm{~kJ} \mathrm{~mol}^{-1}
\end{gathered}
$$

Methane can be easily stored, transported, and converted back into electric energy while solely employing existing infrastructure and technology. At the same time, $\mathrm{CO}_{2}$ from mobile and fixed sources can be utilized, which can have an important environmental impact by reducing anthropogenic greenhouse gas emissions. ${ }^{42}$ Abundant work has been done on developing catalysts for $\mathrm{CO}_{2}$ methanation. Typical methanation catalysts are based on transition metals $(\mathrm{Ni}, \mathrm{Co}, \mathrm{Fe})$, and sometimes precious metals $(\mathrm{Ru}, \mathrm{Rh}, \mathrm{Pd})$, which can work alone or promote another material. ${ }^{40,43}$

To explore the potential of ceramic papers and other fibrous materials as support structures for catalytic layers, it is essential to understand their advantages and limitations. This allows us to implement them for suitable applications and to further develop the materials by introducing modifications through catalyst design and synthesis in the future. This work aims at gaining insight into reaction engineering aspects of ceramic paper-based catalysts, using $\mathrm{CO}_{2}$ methanation over $\mathrm{Ni}$ as a test reaction. The exothermic properties of the reaction and the relatively high reaction rates allow to explore the transport resistances the fibrous structure could present that limit their applicability. The focus of the present paper is thus laid on the performance of ceramic paper catalysts in terms of the different mass and heat transport phenomena and the potential productivity of more highly active catalyst layers, which can be obtained through improved catalyst synthesis methods. A fixed-bed reactor model was developed with the aim of describing fibrous catalysts and allowing changes in parameters and correlations to represent different structures for further work. To describe the activity of ceramic paper catalysts, experiments were carried out. The results were fitted with the model, using known kinetic rate equations, to obtain the relevant parameters. A simulation study was then performed to determine the efficiency of a ceramic paper catalyst in a fixedbed reactor and analyze the efficiency losses caused by heat and mass transport resistances. In addition, a sensitivity study focusing on heat transfer was conducted. The results allow us to understand the potential of ceramic paper catalytic supports and identify the aspects that must be improved from a reaction engineering perspective.

\section{EXPERIMENTAL SECTION}

2.1. Catalysts. Ceramic papers were prepared using a papermaking technique with a dual polyelectrolyte retention system that uses both cationic and anionic polyelectrolytes. The cationic polymer was poly(vinyl amine) (Luredur PR 8095), and the anionic polymer was anionic polyacrylamide (A-PAM) from Ashland. Refractory ceramic fibers (50 wt \% $\mathrm{SiO}_{2}, 48$ wt $\% \mathrm{Al}_{2} \mathrm{O}_{3}$, and 2 wt $\%$ impurities) were obtained from a ceramic insulation mat from CARBO. The fibers were separated from the particulate material by a process of dispersion in water and elutriation. Besides the ceramic fibers that constitute the finished ceramic paper, cellulosic fibers from a commercial bleached softwood Kraft pulp were also incorporated to enhance retention and mat formation. Nyacol 
$\mathrm{Al}_{2} \mathrm{O}_{3}$ (colloidal pseudoboehmite suspension) was used as a binder to produce easy-to-handle paper sheets. A calcination step after sheet formation eliminated the cellulosic fibers and allowed the pseudoboehmite binder transition toward $\gamma$ $\mathrm{Al}_{2} \mathrm{O}_{3}{ }^{4444}$

In a stirred batch reactor containing $1 \mathrm{~L}$ of a $0.01 \mathrm{M} \mathrm{NaCl}$ solution, the components of the slurry were added sequentially in the following order: $150 \mathrm{~g}$ of an aqueous A-PAM polyelectrolyte solution $\left(1 \mathrm{~g} \mathrm{~L}^{-1}\right), 10 \mathrm{~g}$ of ceramic fibers from an insulation mat, $15 \mathrm{~g}$ of Nyacol colloidal $\mathrm{Al}_{2} \mathrm{O}_{3}, 2.5 \mathrm{~g}$ of cellulosic fibers, and $66 \mathrm{~g}$ of an aqueous Luredur polyelectrolyte solution $\left(1 \mathrm{~g} \mathrm{~L}^{-1}\right)$. The resulting suspension was used to produce a handsheet by the SCAN standard method (SCAN-C 26:76 and SCAN-M 5:76) for cellulosic paper sheets but applying double the standard pressing pressure $(37.5 \mathrm{kPa})$. Two pressing steps were carried out to remove as much water as possible. The wet sheet was dried under controlled conditions ( $296 \mathrm{~K}$ and $50 \% \mathrm{RH}$ ) overnight and finally calcined at $823 \mathrm{~K}$ for $2 \mathrm{~h}$ in a muffle furnace under static air. The obtained ceramic paper sheets were circular, $165 \mathrm{~mm}$ in diameter, and $2 \mathrm{~mm}$ thick. Using a hole punch tool, $10 \mathrm{~mm}$ circular discs were cut from the sheet to be impregnated with Ni later. Extra ceramic paper discs were cut and kept blank, with no addition of catalytic components.

The addition of $\mathrm{Ni}$ was carried out by impregnating the ceramic paper discs dropwise with aqueous solutions of $\mathrm{Ni}\left(\mathrm{NO}_{3}\right)_{2}$ until saturation at $5 \mathrm{~mL} \mathrm{~g}^{-1}$ ceramic paper. The precursor solutions were prepared by dissolving $\mathrm{Ni}\left(\mathrm{NO}_{3}\right)_{2}$. $6 \mathrm{H}_{2} \mathrm{O}$ in deionized water. To obtain catalytic ceramic paper discs containing 2.6, 5, and $10 \mathrm{wt} \% \mathrm{Ni}$, the concentrations of $\mathrm{Ni}\left(\mathrm{NO}_{3}\right)_{2}$ in the solutions were $0.088,0.17$, and $0.34 \mathrm{M}$, respectively. After impregnation, the samples were dried at 353 $\mathrm{K}$ overnight and calcined in air at $673 \mathrm{~K}$ for $2 \mathrm{~h}$.

Microcomputer tomography (micro-CT) was used to measure porosity and the size of the void spaces between the fibers. A Bruker Skyscan 1172 device was used, and the source voltage was $44 \mathrm{kV}$ with a current of $226 \mu \mathrm{A}$. The images have a spatial resolution of $2.07 \mu \mathrm{m} \mathrm{pxl}^{-1}$. An image was recorded every $0.2^{\circ}$. The $3 \mathrm{D}$ structure was reconstructed with NRecon software from Bruker. The specific internal surface area of the porous material was measured using $\mathrm{N}_{2}$ physisorption at $77 \mathrm{~K}$ performed with a 3Flex surface analyzer device from Micromeritics. The internal surface area was calculated via the Brunauer-Emmett-Teller (BET) model in the $p / p_{0}$ region between 0.05 and 0.25 . Scanning electron microscopy (SEM) images were taken with a JEOL JSM-35C device operating at $20 \mathrm{kV}$ and used to determine the average fiber size of the ceramic papers. Samples were glued to the sample holder with $\mathrm{Ag}$ and then coated with a thin layer of $\mathrm{Au}$ to improve the images. Properties of the finished ceramic paper material are given in Table 1.

\section{Table 1. Textural Properties of Ceramic Paper}

\begin{tabular}{ll}
\multicolumn{1}{c}{ property (characterization technique) } & \multicolumn{1}{c}{ value $^{a}$} \\
average fiber diameter (SEM) & $6 \mu \mathrm{m}$ \\
porosity (X-ray microtomography) & 0.75 \\
average size void space between fibers (X-ray & $26 \mu \mathrm{m}$ \\
microtomography) & $20 \mathrm{~m}^{2} \mathrm{~g}^{-1}$ \\
BET surface area $\left(\mathrm{N}_{2}\right.$ physisorption)
\end{tabular}

${ }^{a}$ The values were not significantly modified after the addition of catalytic components.
2.2. Catalytic Tests. An oven-heated fixed-bed flow reactor was used for evaluating the catalytic performance of the prepared materials. The gas mixture is continuously fed from the top by means of mass flow controllers. The stainless steel reactor was constructed with a $10 \mathrm{~mm}$ pipe at the top and a 9 $\mathrm{mm}$ pipe at the bottom, welded together providing support for the catalytic bed, which is placed inside the $10 \mathrm{~mm}$ section (Figure 1). An in-line gas chromatograph equipped with a

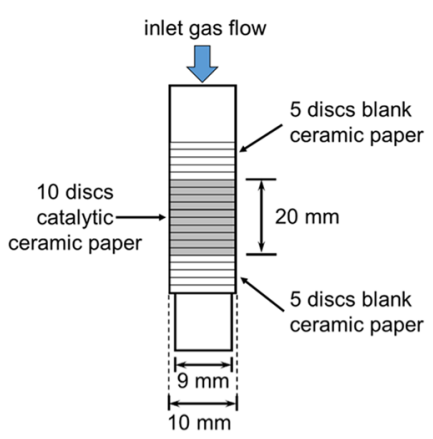

Figure 1. Reactor assembly for the samples of catalytic ceramic paper.

thermal conductivity detector (TCD) was used to measure inlet and outlet concentrations of $\mathrm{CO}_{2}, \mathrm{CH}_{4}, \mathrm{CO}$, and Ar. The temperature was measured using a thermocouple inside the reactor before the gas flow of reactants enters the ceramic paper packing, which corresponds to the inlet temperature. It is hardly possible to measure the temperature inside the catalytic bed because the introduction of a thermocouple would require drilling a concentric hole through the ceramic paper, which disrupts the structure and leads to bypass flow and thus measurement errors. Temperature measurements were done previously with an empty reactor at the position of the catalytic bed. The results confirm homogeneous temperature distribution. Additionally, the temperature profiles for the experiments were checked with simulations, which is discussed in Section 4.

The reactor was assembled in the same manner for all samples. Five blank ceramic paper discs were piled inside the reactor at the bottom of the $10 \mathrm{~mm}$ pipe section to provide support for the catalyst. Then, 10 catalytic ceramic paper discs were piled to form the catalytic bed, which measured $20 \mathrm{~mm}$ in length. Finally, five more blank ceramic paper discs were placed on top to help fix the catalyst and aid in gas flow distribution.

The catalysts were reduced in situ in a flow of $50 \mathrm{~mL} \mathrm{~min}^{-1}$ $\mathrm{H}_{2}$ at $673 \mathrm{~K}$ and $300 \mathrm{kPa}$ for $12 \mathrm{~h}$. The $\mathrm{CO}_{2}$ methanation catalytic tests were performed at $300 \mathrm{kPa}$ and different temperatures $(553,573,593$, and $623 \mathrm{~K})$ with a total inlet flow of $60 \mathrm{~mL} \mathrm{~min}{ }^{-1}$. The inlet compositions were measured by gas chromatography and are listed in Table 2.

A measurement was carried out with a blank ceramic paper support without $\mathrm{Ni}$, using the same reaction mixture, flow rate, and pressure as for the $\mathrm{Ni}$ catalysts and a higher temperature range $(553-713 \mathrm{~K})$. Neither $\mathrm{CH}_{4}$ nor $\mathrm{CO}$ formation was observed in this experiment.

\section{MODEL DEVELOPMENT AND SIMULATION}

3.1. Modeling of a Fixed-Bed Reactor. The cooled fixed-bed reactor in steady state is described by a heterogeneous $1 \mathrm{D}-1 \mathrm{D}$ model, with plug-flow behavior and neglecting axial dispersion. Figure 2 shows a schematic representation of the reactor. 
Table 2. Samples Used for Each Experiment and Compositions of the Inlet Streams

\begin{tabular}{|c|c|c|c|c|c|}
\hline sample & denomination & $\begin{array}{l}\text { sample mass } \\
(\mathrm{mg})\end{array}$ & $\begin{array}{l}\text { nominal } \mathrm{Ni} \text { content in } \\
\text { reactor }(\mathrm{mg})\end{array}$ & $\begin{array}{l}\text { real Ni content in reactor } \\
\qquad(\mathrm{mg})^{a}\end{array}$ & $\begin{array}{l}\text { molar composition measured at inlet, } \\
\qquad \mathrm{CO}_{2} / \mathrm{H}_{2} / \mathrm{Ar}\end{array}$ \\
\hline $\begin{array}{l}\text { ceramic paper with } \\
2.6 \text { wt } \% \mathrm{Ni}\end{array}$ & $\begin{array}{l}2.6 \% \mathrm{Ni} / \\
\text { PCer }\end{array}$ & 380.1 & 9.6 & 9.9 & $1 / 3.1 / 1.02$ \\
\hline $\begin{array}{l}\text { ceramic paper with } 5 \text { wt } \% \\
\mathrm{Ni}\end{array}$ & $5 \% \mathrm{Ni} / \mathrm{PCer}$ & 385.5 & 18.3 & 17.8 & $1 / 3.38 / 1$ \\
\hline $\begin{array}{l}\text { ceramic paper with } \\
10 \text { wt } \% \mathrm{Ni}\end{array}$ & $10 \% \mathrm{Ni} / \mathrm{PCer}$ & 426.1 & 38.7 & 36.5 & $1 / 3.39 / 1$ \\
\hline
\end{tabular}

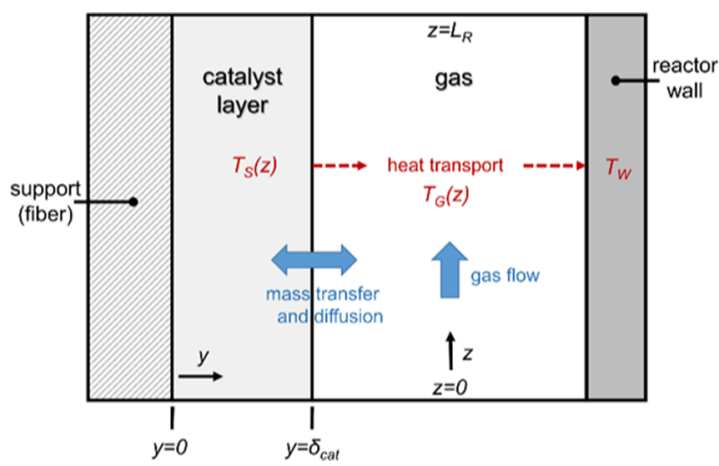

Figure 2. Schematic representation of the reactor for the model development.

The model was built with the aim of describing the fibrous material in a way that is applicable to replicate the performed experiments, as well as to study variations in fiber parameters in the future (such as fiber diameter and catalyst coating thickness) and adapt them to other materials (pellets, monoliths) by only changing parameters and correlations. For this reason, the fibers are modeled as inert support with a layer of catalytic material covering its surface, allowing us to describe internal mass transport. The pore diameter, catalyst porosity, and tortuosity were assumed to be typical values $\left(d_{\text {pore }}=10 \mathrm{~nm}, \varepsilon_{\text {cat }}=0.5, \tau_{\text {cat }}=4\right)$.

Further assumptions used to develop the model are chosen as follows. The gas flow behaves as an ideal gas and contains the following components: $\mathrm{H}_{2}, \mathrm{CO}, \mathrm{CO}_{2}, \mathrm{CH}_{4}, \mathrm{H}_{2} \mathrm{O}$, and Ar. The physical and thermodynamic properties are assumed to be independent of temperature. The catalyst bed is assumed to contain uniform-sized fibers and constant bulk porosity over the whole reactor bed. A uniform layer of the catalyst of thickness $\delta_{\text {cat }}$ is assumed to cover each fiber. The interplay between diffusion and chemical reaction inside the catalyst phase is described by one effectiveness factor for each reaction, which varies along the reactor bed. The solid material is assumed to be isothermal at every axial position so that there is no development of a temperature profile inside a solid fiber. The reactor cooling is described by an effective heat transfer coefficient between the gas bulk and the cooled reactor wall, $h_{\text {eff }}$ considering a constant temperature of the wall along the reactor, $T_{\mathrm{w}}$. The reactor is thus described by the following set of balance equations.

Mass balance in the gas phase

$$
0=-\frac{\mathrm{d}}{\mathrm{d} z} u_{\mathrm{g}}(z) c_{\mathrm{g}, i}(z)-k_{\mathrm{gs}} a_{\mathrm{gs}}\left[c_{\mathrm{g}, i}(z)-c_{\mathrm{s}, i}\left(z, \delta_{\mathrm{cat}}\right)\right]
$$

Boundary condition, reactor inlet

$$
c_{\mathrm{g}, i}(z=0)=c_{\mathrm{g}, i}^{0}
$$

Mass balance in the solid phase (cylindrical geometry)

$$
0=D_{\mathrm{eff}, i}\left[\frac{\partial^{2} c_{\mathrm{s}, i}(z, y)}{\partial y^{2}}+\frac{1}{y} \frac{\partial c_{\mathrm{s}, i}(z, y)}{\partial y}\right]+\rho_{\mathrm{cat}} \sum_{j} \nu_{i, j} r_{j}(z, y)
$$

Boundary conditions, catalyst center, and external surface

$$
\begin{aligned}
& \frac{\partial c_{\mathrm{s}, i}(z, 0)}{\partial y}=0 \\
& \begin{aligned}
0= & k_{\mathrm{gs}} a_{\mathrm{gs}}\left[c_{\mathrm{g}, i}(z)-c_{\mathrm{s}, i}\left(z, \delta_{\mathrm{cat}}\right)\right] \\
& \quad+x_{\text {cat }} \rho_{\text {cat }} \sum_{j} \nu_{i, j} r_{j}\left(z, \delta_{\text {cat }}\right) \eta_{j}(z)
\end{aligned}
\end{aligned}
$$

Heat balance in the gas

$$
\begin{aligned}
0= & -c_{\mathrm{p}, \mathrm{g}} \rho_{\mathrm{g}} u_{\mathrm{g}} \frac{\mathrm{d}}{\mathrm{d} z}\left[T_{\mathrm{g}}(z)\right]-\frac{4}{d_{\text {tube }}} h_{\mathrm{eff}}\left[T_{\mathrm{g}}(z)-T_{\mathrm{w}}(z)\right] \\
& +h_{\mathrm{gs}} a_{\mathrm{gs}}\left(T_{\mathrm{s}}-T_{\mathrm{g}}\right)
\end{aligned}
$$

Boundary condition, reactor inlet

$$
T_{\mathrm{g}}(z=0)=T_{0}
$$

Heat balance at the solid surface

$$
\begin{aligned}
0= & h_{\mathrm{gs}} a_{\mathrm{gs}}\left[T_{\mathrm{s}}(z)-T_{\mathrm{g}}(z)\right]+ \\
& x_{\text {cat }} \rho_{\text {cat }} \sum_{j} r_{j}\left(z, \delta_{\mathrm{cat}}\right) \eta_{j}(z) \Delta H_{\mathrm{r}, j}\left(T_{\mathrm{s}}(z)\right)
\end{aligned}
$$

Momentum balance

$$
p(z)=p(0)-\frac{\Delta p}{L} z
$$

Since the reactions present change in the number of moles, the molar flow of the gas stream decreases and its velocity changes. This can be described by the continuity equation (eq 10).

$$
u_{\mathrm{g}}(z)=u_{\mathrm{g}}(0) \frac{\rho_{\mathrm{g}}(0)}{\rho_{\mathrm{g}}(z)}
$$

The effectiveness factor for cylindrical geometry is given by eq 11.

$$
\eta_{j}(z)=\frac{2}{\delta_{\text {cat }}^{2}} \frac{\int_{y=0}^{\delta_{\text {cat }}}(z, y) y \mathrm{~d} y}{r_{j}\left(z, y=\delta_{\text {cat }}\right)}
$$

3.2. Correlations and Data. For a packed bed of spheres, the pressure drop is described by the Ergun equation (eq 12). Reichelt and Jahn ${ }^{32}$ found that the Ergun equation accurately predicts the pressure drop through a packed bed of fibers when 
Table 3. Kinetic Parameters from Xu and Froment ${ }^{49}$

\begin{tabular}{|c|c|c|c|c|c|c|c|}
\hline parameter & $k_{1}(648 \mathrm{~K})$ & $k_{2}(648 \mathrm{~K})$ & $k_{3}(648 \mathrm{~K})$ & $K_{\mathrm{CO}}(648 \mathrm{~K})$ & $K_{\mathrm{H}_{2}}(648 \mathrm{~K})$ & $K_{\mathrm{CH}_{4}}(823 \mathrm{~K})$ & $K_{\mathrm{H}_{2} \mathrm{O}}(823 \mathrm{~K})$ \\
\hline units & $\mathrm{kmol} \mathrm{bar}^{0.5} \mathrm{~kg}_{\text {cat }}{ }^{-1} \mathrm{~h}^{-1}$ & $\mathrm{kmol} \mathrm{kg}_{\text {cat }}^{-1} \mathrm{~h}^{-1}$ bar $^{-1}$ & $\mathrm{kmol} \mathrm{bar}^{0.5} \mathrm{~kg}_{\text {cat }}{ }^{-1} \mathrm{~h}^{-1}$ & $\mathrm{bar}^{-1}$ & bar $^{-1}$ & $\mathrm{bar}^{-1}$ & 1 \\
\hline value & $1.842 \times 10^{-4}$ & 7.558 & $2.193 \times 10^{-5}$ & 40.91 & 0.02960 & 0.1791 & 0.4152 \\
\hline
\end{tabular}

the Sauter diameter for a long fiber (eq 14) is used as the characteristic diameter. They also generalized a correlation for external mass transfer for a packed bed of fibers (eq 13). The original correlation was developed by Reichelt et al. for external mass transfer in a packed bed of spheres. ${ }^{45}$

$$
\begin{aligned}
\frac{\Delta p}{L}= & 150 \frac{\left(1-\varepsilon_{\mathrm{B}}\right)^{2} \mu_{\mathrm{g}} u_{\mathrm{g}}}{\varepsilon_{\mathrm{B}}^{3} d^{2}}+1.75 \frac{\left(1-\varepsilon_{\mathrm{B}}\right) \rho_{\mathrm{g}} u_{\mathrm{g}}{ }^{2}}{\varepsilon_{\mathrm{B}}^{3} d} \\
S h_{\mathrm{S}}= & S h_{\mathrm{S}, R e_{\mathrm{S}}=0}+1.26 \\
& {\left[\frac{1-\left(1-\varepsilon_{\mathrm{B}}\right)^{5 / 3}}{2-3\left(1-\varepsilon_{\mathrm{B}}\right)^{1 / 3}+3\left(1-\varepsilon_{\mathrm{B}}\right)^{5 / 3}-2\left(1-\varepsilon_{\mathrm{B}}\right)^{2}}\right]^{1 / 3} } \\
& \times\left[0.991 P e_{\mathrm{S}}^{1 / 3}+\frac{0.037 R e_{\mathrm{S}}^{0.8} S c}{1+2.44 R e_{\mathrm{S}}^{-0,1}\left(S c^{2 / 3}-1\right)}\right]
\end{aligned}
$$

$$
d_{\mathrm{S}}=\frac{6}{S_{\mathrm{v}, \mathrm{f}}}=1.5 d_{\mathrm{f}}
$$

The effective diffusion inside the solid was considered to have molecular and Knudsen contributions, according to eq 15, where $D_{\mathrm{K}, i}$ is given by eq 16 .

$$
\begin{aligned}
& D_{\mathrm{eff}, i}=\left(D_{\mathrm{m}, i}^{-1}+D_{\mathrm{K}, i}^{-1}\right)^{-1} \frac{\varepsilon_{\mathrm{cat}}}{\tau_{\mathrm{cat}}} \\
& D_{\mathrm{K}, i}=\frac{d_{\mathrm{p}}}{3} \sqrt{\frac{8 R T}{\pi M_{i}}}
\end{aligned}
$$

To the authors' knowledge, no correlations have been published for fibrous materials that estimate heat transfer between a solid and gas. To estimate a heat transfer coefficient, $h_{\mathrm{gs}}$, the Levêque analogy was used. This analogy provides a correlation between pressure drop through the Hagen number and heat transfer (eq 17). Martin ${ }^{46}$ showed the validity of the analogy for different geometries, including packed beds of nonspherical solids and crossed-rod matrices. More recently, Dietrich $^{47}$ showed that the analogy also correlates the tendencies shown by experimental data from ceramic sponges. The frictional fraction $f_{\mathrm{r}}=0.46$ for staggered crossed-rod matrices was used.

$$
\frac{N u}{\operatorname{Pr}^{1 / 3}}=\frac{S h}{S c^{1 / 3}}=0.4038\left(2 f_{\mathrm{r}} \mathrm{Hg} \frac{d_{\mathrm{h}}}{L}\right)^{1 / 3}
$$

For the heat transfer coefficient between the gas phase and the cooled wall $\left(h_{\text {eff }}\right)$, a radial heat transfer contribution is considered, as well as a contribution for transfer near the wall. According to de Wasch and Froment, ${ }^{48}$ the following approximation can be made, where $\lambda_{\text {eff }}$ is the effective radial thermal dispersion of the bed and $h_{\mathrm{w}}$ is the coefficient for the heat transfer near the wall

$$
\frac{1}{h_{\mathrm{eff}}}=\frac{1}{h_{\mathrm{w}}}+\frac{d_{\text {tube }}}{8 \lambda_{\mathrm{eff}}}
$$

To the authors' knowledge, no correlations for heat transfer toward the wall in fibrous materials have been published. Foams can be considered similar in structure to a bed filled with fibers, so correlations published by Wallenstein et al. ${ }^{33}$ for ceramic sponges were used for the simulations of a packed bed of fibers. Certain challenges can arise from this approximation, in particular, foams are made of a continuous solid phase, so there might be differences with the fibers with regard to heat transfer through conduction. Nevertheless, this approach was chosen for its simplicity and the availability of information. The effective radial thermal dispersion of the bed has stagnant and dynamic contributions. The stagnant contribution $\lambda_{0}$ is divided into parallel and serial contributions. A parameter $b$ (eq 20) weighs the ratio of parallel to serial heat transfer and is related to the degree of continuity of the solid phase. Since no correlation for calculating $b$ is available for ceramic papers, a typical value of 0.63 for ceramic sponges is used, due to the structural similarity of ceramic sponges and papers. During sensitivity analysis, the value for $b$ is varied to study the effect of this parameter on the heat transfer characteristics under reaction conditions.

$$
\begin{aligned}
& \frac{\lambda_{\text {eff }}}{\lambda_{\mathrm{g}}}=\frac{\lambda_{0}}{\lambda_{\mathrm{g}}}+\frac{P e_{\mathrm{T}}}{8} \\
& \lambda_{0}=b\left[\frac{\varepsilon_{\mathrm{B}}}{\lambda_{\mathrm{g}}}+\frac{\left(1-\varepsilon_{\mathrm{B}}\right)}{\lambda_{\mathrm{s}}}\right]^{-1}+(1-b)\left[\varepsilon_{\mathrm{B}} \lambda_{\mathrm{g}}+\left(1-\varepsilon_{\mathrm{B}}\right) \lambda_{\mathrm{s}}\right]
\end{aligned}
$$

The heat transfer coefficient near the wall $\left(h_{\mathrm{w}}\right)$ is calculated through the corresponding Nusselt number. The $N u_{\mathrm{w}}$ is a function of the ratio of the mixing length $x_{\mathrm{f}}$ to the tube diameter. The mixing length is the sum of the strut and the window diameter of the sponge multiplied by 0.39 for sponges with round struts (similar to fibers). Using this estimation for ceramic paper, it gives a value of $x_{\mathrm{f}}=13 \mu \mathrm{m}$.

$$
N u_{\mathrm{w}}=0.31+\left(0.04+1.54 \frac{x_{\mathrm{f}}}{d_{\text {tube }}}\right) \operatorname{Pr}^{1 / 3} \operatorname{Re}^{3 / 4}
$$

3.3. Kinetics. The Langmuir-Hinshelwood-HougenWatson rate equations proposed by $\mathrm{Xu}$ and Froment ${ }^{49}$ (eqs 22-25) were chosen for simulating the methanation of $\mathrm{CO}_{2}$ over a $\mathrm{Ni}$ catalyst along with the kinetic parameters given in Table 3. Scheme 1 shows the underlying reaction scheme accounting for the reverse $\mathrm{CO}$ methanation $\left(r_{1}\right.$, eq 22), reverse $\mathrm{CO}_{2}$ methanation $\left(r_{2}\right.$, eq 23$)$, and water-gas shift reaction $\left(r_{3}\right.$, eq 24) on a Ni/ $\mathrm{MgAl}_{2} \mathrm{O}_{4}$ catalyst. Equation 25 represents the common denumerator for all kinetic rate equations. The kinetic parameters are obtained from experiments performed at temperatures between 573 and $673 \mathrm{~K}$ and pressures between 300 and $1000 \mathrm{kPa}$ at undiluted feed gas compositions.

$$
r_{1}=\frac{k_{1}}{p_{\mathrm{H}_{2}}^{2.5}}\left(p_{\mathrm{CH}_{4}} p_{\mathrm{H}_{2} \mathrm{O}}-\frac{p_{\mathrm{H}_{2}}^{3} p_{\mathrm{CO}}}{K_{1}}\right) / \mathrm{DEN}^{2}
$$


Scheme 1. Reaction Scheme for Methanation of $\mathrm{CO}_{2}$ Over a $\mathrm{Ni} / \mathrm{MgAl}_{2} \mathrm{O}_{4}$ Catalyst $^{49}$

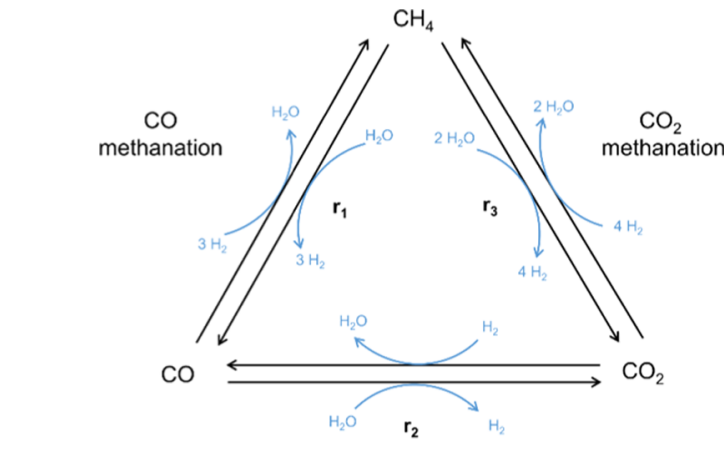

water-gas shift

$$
\begin{aligned}
& r_{2}=\frac{k_{2}}{p_{\mathrm{H}_{2}}}\left(p_{\mathrm{CO}} p_{\mathrm{H}_{2} \mathrm{O}}-\frac{p_{\mathrm{H}_{2}} p_{\mathrm{CO}_{2}}}{K_{2}}\right) / \mathrm{DEN}^{2} \\
& r_{3}=\frac{k_{3}}{p_{\mathrm{H}_{2}}^{3.5}}\left(p_{\mathrm{CH}_{4}} p_{\mathrm{H}_{2} \mathrm{O}}^{2}-\frac{p_{\mathrm{H}_{2}}^{4} p_{\mathrm{CO}_{2}}}{K_{3}}\right) / \mathrm{DEN}^{2} \\
& \mathrm{DEN}=1+K_{\mathrm{CO}} p_{\mathrm{CO}}+K_{\mathrm{H}_{2}} p_{\mathrm{H}_{2}}+K_{\mathrm{CH}_{4}} p_{\mathrm{CH}_{4}}+K_{\mathrm{H}_{2} \mathrm{O}} \\
& p_{\mathrm{H}_{2} \mathrm{O}} / p_{\mathrm{H}_{2}}
\end{aligned}
$$

3.4. Simulation. The model was implemented and solved using the software Aspen Custom Modeler. To study the factors that affect the performance of a structured ceramic paper catalyst, simulations were performed with variations of different parameters. Güttel and Turek ${ }^{50}$ carried out a study on reactors for Fischer-Tropsch synthesis, where they mathematically defined a reactor efficiency (eq 26) and efficiency losses (differences of the reactor efficiency to unity) caused by heat transfer resistance (eq 27), internal mass transfer resistance (eq 28), and external mass transfer resistance (eq 29). The losses caused by heat transfer resistance are due to the decrease in achievable reaction rate when the mean reaction temperature is lower than the maximum temperature. These parameters, calculated with the rate of formation of $\mathrm{CH}_{4}$, were used in the present work. As can be seen in Scheme $1, \mathrm{CH}_{4}$ is formed through two reactions, so the rate of formation can be calculated with eq 30. Similarly, $r_{\mathrm{CH}_{4} \text {,eff }}$ (eq 31) refers to the effective rate of formation, considering internal diffusion limitations.

$$
\begin{gathered}
E_{\text {reactor }}=\frac{\int_{0}^{L_{\mathrm{R}}} r_{\mathrm{CH}_{4}, \text { eff }}\left(c_{\mathrm{s}, i}\left(\delta_{\text {cat }}\right), T_{\mathrm{s}}\right) \mathrm{d} z}{\int_{0}^{L_{\mathrm{R}}}{ }^{\mathrm{CH}_{4}}\left(c_{\mathrm{g}, i}\left(\delta_{\text {cat }}\right), T_{\text {max }}\right) \mathrm{d} z} \\
\Delta E_{\mathrm{T}}=\frac{\int_{0}^{L_{\mathrm{R}}} r_{\mathrm{CH}_{4}, \text { eff }}\left(c_{\mathrm{s}, i}\left(\delta_{\text {cat }}\right), T_{\mathrm{s}}\right) \mathrm{d} z}{\int_{0}^{L_{\mathrm{R}}} r_{\mathrm{CH}_{4}}\left(c_{\mathrm{g}, i}, T_{\mathrm{s}}\right) \mathrm{d} z}-E_{\text {reactor }} \\
\Delta E_{\text {int }}=1-\frac{\int_{0}^{L_{\mathrm{R}}} r_{\mathrm{CH}_{4}, \text { eff }}\left(c_{\mathrm{s}, i}\left(\delta_{\text {cat }}\right), T_{\mathrm{s}}\right) \mathrm{d} z}{\int_{0}^{L_{\mathrm{R}}} r_{\mathrm{CH}_{4}}\left(c_{\mathrm{s}, i}\left(\delta_{\text {cat }}\right), T_{\mathrm{s}}\right) \mathrm{d} z} \\
\Delta E_{\text {ext }}=1-\left(E_{\text {reactor }}+\Delta E_{\mathrm{T}}+\Delta E_{\text {int }}\right)
\end{gathered}
$$

$$
\begin{aligned}
& r_{\mathrm{CH}_{4}}=-r_{1}-r_{3} \\
& r_{\mathrm{CH}_{4}, \text { eff }}=-r_{1} \eta_{1}-r_{3} \eta_{3}
\end{aligned}
$$

For the simulations, the concentrations were converted to partial pressures as balancing variables using the ideal gas equation for both the gas bulk and the solid catalyst interior (eq 32). This allowed us to combine the equation system with the kinetic expressions.

$$
p_{i}=c_{i} R T
$$

\section{FITTING OF EXPERIMENTAL DATA AND ESTIMATION OF KINETIC PARAMETERS}

The experimental results from the test catalyst were reproduced by manually fitting the values of $\mathrm{CO}_{2}$ conversion with the model described in Section 3.1. As previously discussed, the model assumes a uniform porous layer of catalyst deposited over the fibers. The layer is proposed in the model to study potential internal mass transfer limitations. In the prepared catalysts, the impregnated $\mathrm{Ni}$ forms heterogeneous aggregates on the surface of the fibers, which suggests the absence of diffusional limitations. The catalyst layer thickness was calculated theoretically based on the Ni content and on the catalyst density from $\mathrm{Xu}$ and Froment catalyst. The obtained values for the corresponding hypothetical catalyst layer thickness are $0.1,0.2$, and $0.4 \mu \mathrm{m}$ for $2.6 \% \mathrm{Ni} / \mathrm{PCer}, 5 \%$ $\mathrm{Ni} / \mathrm{PCer}$, and $10 \% \mathrm{Ni} / \mathrm{PCer}$, respectively. The absence of internal diffusional limitations with these parameters was confirmed with the simulations. The external surface area of the fibers per bed volume $\left(a_{\mathrm{gs}}\right)$ was calculated assuming a bed of $6 \mu \mathrm{m}$ diameter fibers with a bed porosity of 0.75 , the result being $1.67 \times 10^{5} \mathrm{~m}^{-1}$. This high value makes it foreseeable that the gas-solid mass transfer and heat transfer is enhanced.

As a fitting parameter, an activity factor $a_{\mathrm{f}}$ was introduced, which multiplies the kinetic constants in all three proposed reaction rates together. The activity factor includes differences in the activity of the catalysts, namely, factors like the number of active sites, nature of the active sites (presence of different $\mathrm{Ni}$ species ${ }^{51}$ ), and interaction with the support. The other fitting parameters were the activation energies for the three reactions proposed in the kinetic rate equations to account for the temperature influence on the kinetic constants. All other parameters for describing the reaction kinetics are taken from $\mathrm{Xu}$ and Froment ${ }^{49}$ without further changes. The experiments were assumed to be isothermal at every temperature presented. This was verified with the simulations that include the heat balances. The results show slight axial temperature increases inside the reactor, the most extreme case being a $3 \mathrm{~K}$ temperature rise for the ceramic paper with $10 \% \mathrm{Ni}$ with an inlet temperature of $623 \mathrm{~K}$. Figure 3 shows the results for $\mathrm{CO}_{2}$ conversion and $\mathrm{CH}_{4}$ selectivity obtained with the different catalysts. The scattered data show the experimental results, while the lines show the fittings made with the model.

The dotted curve in the plot represents the equilibrium conversions for the experimental conditions $\left(300 \mathrm{kPa}, x_{\mathrm{CO}_{2}}^{0}=\right.$ $\left.0.187, x_{\mathrm{H}_{2}}^{0}=0.623, x_{\mathrm{Ar}}^{0}=0.189\right)$, which are slightly deviated from stoichiometry. The simulation results adequately represent the experimental data with regard to the $\mathrm{CO}_{2}$ conversion. For the measurements corresponding to catalytic ceramic papers, the increase in the catalyst activity is roughly proportional to the $\mathrm{Ni}$ content, as doubling the Ni percentage doubles the conversion for values lower than $20 \%$. As observed 

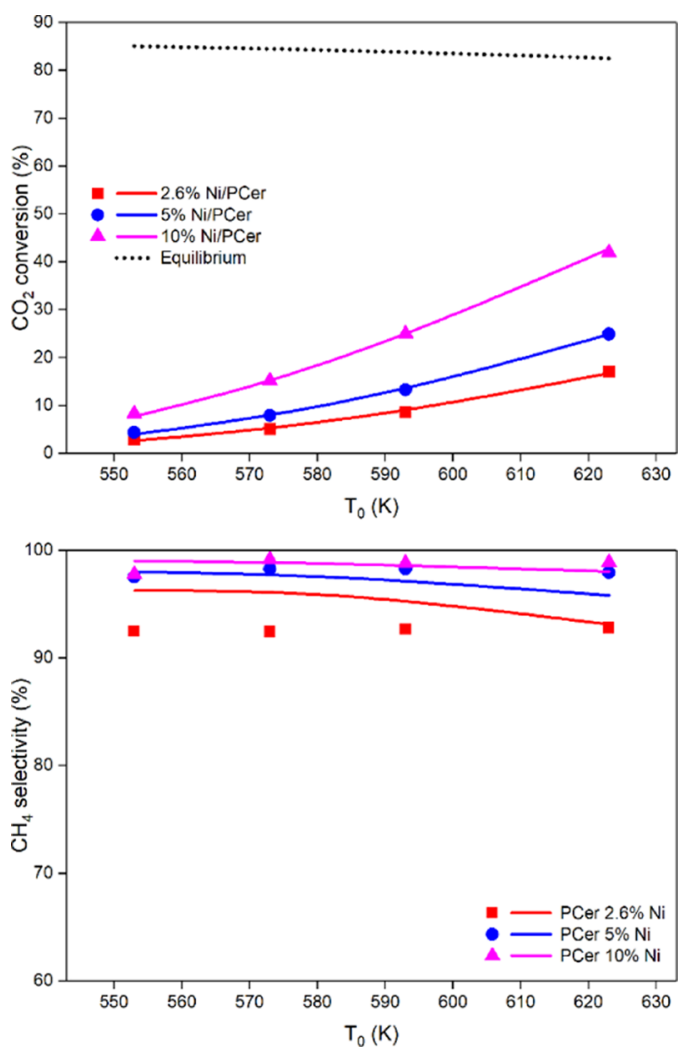

Figure 3. $\mathrm{CO}_{2}$ conversion and selectivity toward $\mathrm{CH}_{4}$; scattered data correspond to experiments and lines correspond to fitted values from simulations; the equilibrium selectivity is close to $100 \%$ for the working temperature range.

in Table 4, the activity factors for the ceramic paper samples are comparable, especially for $5 \% \mathrm{Ni} / \mathrm{PCer}$ and $10 \% \mathrm{Ni} / \mathrm{PCer}$.

Table 4. Values of the Fitting Parameters Activation Energy and Activity Factor Obtained with Coefficients of Determination $R^{2}>0.99$ for Each Material

\begin{tabular}{lcccc}
\multicolumn{1}{c}{ catalyst } & $a_{\mathrm{f}}^{a} / 1$ & $\begin{array}{c}E_{\mathrm{a} 1}\left(\mathrm{~kJ} \mathrm{~mol}^{-1}\right), \\
\text { eq } 22\end{array}$ & $\begin{array}{c}E_{\mathrm{a} 2}\left(\mathrm{~kJ} \mathrm{~mol}^{-1}\right), \\
\text { eq } 23\end{array}$ & $\begin{array}{c}E_{\mathrm{a} 3}\left(\mathrm{~kJ} \mathrm{~mol}^{-1}\right), \\
\text { eq } 24\end{array}$ \\
$\begin{array}{l}\mathrm{Ni} / \\
\mathrm{MgAl} \mathrm{O}_{4}{ }^{49}\end{array}$ & 1 & 240.1 & 67.1 & 243.9 \\
$2.6 \% \mathrm{Ni} / \mathrm{PCer}$ & 0.82 & 206.1 & 57.6 & 209.3 \\
$5 \% \mathrm{Ni} / \mathrm{PCer}$ & 0.66 & & \\
$10 \% \mathrm{Ni} / \mathrm{PCer}$ & 0.64 & & \\
\multicolumn{2}{l}{ Listed values are referred to $\mathrm{Ni} / \mathrm{MgAl}_{2} \mathrm{O}_{4}$ catalyst from ref 49.}
\end{tabular}

Since the change in metal loading is accounted for in the catalyst volumetric fraction in the reactor $x_{\text {cat }}$, the activity factor mainly represents the differences in the nature and distribution of the active species, which suggests similar surface characteristics for the ceramic paper samples with different $\mathrm{Ni}$ contents. In this context, the slightly higher activity factor for $2.6 \% \mathrm{Ni} /$ PCer might indicate a higher degree of distribution of the active sites or higher amounts of more active species when a smaller metal loading was incorporated on the ceramic paper fibers, which is a common phenomenon, especially for impregnated catalysts. ${ }^{52}$

The experimental results for all samples were successfully fitted with the same values of activation energy. Such values are slightly lower than those reported by $\mathrm{Xu}$ and Froment ${ }^{49}$ for $\mathrm{Ni} / \mathrm{MgAl}_{2} \mathrm{O}_{4}$. The ceramic paper support, however, is made of alumina and silica fibers, and an alumina binder is used, which acts as support for the active $\mathrm{Ni}$ species. The support of the ceramic fibers thus deviates from that used by $\mathrm{Xu}$ and Froment. As a matter of fact, differences in the morphology and composition of the catalytic supports can modify the values of activation energies, as different $\mathrm{Ni}$ superficial species can appear. Besides, $\mathrm{Xu}$ and Froment developed their kinetics for steam reforming at higher temperatures (773-848 K) and for $\mathrm{CO}_{2}$ methanation at a higher temperature range (573-673 $\mathrm{K})$ than the one considered in this study, which can also cause the slight differences in activation energy. Most studies dealing with methanation on $\mathrm{Ni}$ catalysts with oxide supports do not report activation energies for the three separate reactions but present an apparent activation energy for the formation of $\mathrm{CH}_{4}$, which is often calculated with a power-law, nonreversible reaction approach. The values of apparent activation energy in the literature range from 75 to $120 \mathrm{~kJ} \mathrm{~mol}^{-1}$ for $\mathrm{Ni} / \mathrm{Al}_{2} \mathrm{O}_{3}$ catalysts. $^{53-57}$ If the same approach is applied to the $\mathrm{Ni}$ / $\mathrm{MgAl}_{2} \mathrm{O}_{4}$ catalyst, the apparent activation energy of $118 \mathrm{~kJ}$ $\mathrm{mol}^{-1}$ is found, which is on the higher side of the reported values, while the results obtained for the ceramic paper catalysts are around $80 \mathrm{~kJ} \mathrm{~mol}^{-1}$. In the same vein, Schlereth and Hinrichsen ${ }^{58}$ observed that the $\mathrm{Xu}$ and Froment model slightly overestimated the activation energies when a $\mathrm{Ni} / \mathrm{ZrO}_{2}$ catalyst was used. Ducamp et al. ${ }^{59}$ used a commercial $14-17 \%$ $\mathrm{Ni} / \mathrm{Al}_{2} \mathrm{O}_{3}$ catalyst for $\mathrm{CO}_{2}$ methanation and adjusted the kinetics from $\mathrm{Xu}$ and Froment by estimating their own activation energies, which resulted in values around $10-14 \%$ lower than the original values for the three reactions. Similarly, Oliveira et al. ${ }^{60}$ used a commercial $15 \% \mathrm{Ni} / \mathrm{Al}_{2} \mathrm{O}_{3}$ catalyst for steam reforming. They fit the results with the $\mathrm{Xu}$ and Froment kinetics, as well, obtaining values of activation energies around $10 \%$ lower than the original values. Following the previous arguments and references, it is reasonable to consider that the activation energies for the ceramic paper catalysts are slightly lower than the original values for the $\mathrm{Ni} / \mathrm{MgAl}_{2} \mathrm{O}_{4}$ catalyst. For the rest of this work, it is assumed that the individual activation energies are given by the values listed in Table 4.

The achieved selectivity toward $\mathrm{CH}_{4}$ is over $95 \%$ for the experiments with $5 \% \mathrm{Ni} / \mathrm{PCer}$ and $10 \% \mathrm{Ni} / \mathrm{PCer}$, and the temperature effect on selectivity is quite small. These values are adequately reproduced with the simulations. For $2.6 \% \mathrm{Ni} /$ PCer, the selectivity was somewhat lower, in the order of $92 \%$. At the same time, the simulations show a tendency for lower selectivity when the $\mathrm{Ni}$ content is lower for each temperature. This is due to the lower conversions, since the small amounts of byproduct $\mathrm{CO}$ present would eventually be converted into $\mathrm{CH}_{4}$ if given enough residence time. In addition to this, slight deviations are observed between the measured selectivity and the value obtained by simulation, especially at a lower temperature. This can be explained by the assumption that the activation energy is identical for all three catalysts, which is the case if all materials studied provide identical intrinsic catalytic properties. To account for the different active metal amounts, we only distinguished the materials using the activity factor. The small deviations in selectivity for the 2.6 and $5 \%$ $\mathrm{Ni} / \mathrm{PCe}$ materials indicate that the assumptions on identical activation energies induce some inaccuracies, which is acceptable, considering the complexity in catalyst preparation and testing. 


\section{SIMULATION RESULTS}

A simulation study was carried out to analyze the performance and the main limitations of ceramic paper catalysts. The respective results are the basis for optimal reactor design and to use the degrees of freedom provided by these materials in an optimal manner.

Three sets of simulations were performed. In the first one, the catalytic activity was varied to study the efficiency and efficiency losses of a reactor with a ceramic paper catalyst. In the second and third sets of simulations, the inlet gas temperature and heat transfer were varied to analyze the sensitivity of the maximum temperatures and $\mathrm{CH}_{4}$ yield.

The activation energies fitted to the experimental data were applied, and the activity factors used were 1, 2, 3, and 4 times the value for $10 \% \mathrm{Ni} / \mathrm{PCer}$ (relative activity) to simulate better distribution and surface properties of the active phase, as a result of improved preparation methods. For all simulations, the set inlet pressure was $1000 \mathrm{kPa}$ to achieve high conversions and industrial relevant operating conditions. The inlet gas molar flow rate per cross-sectional area was $10 \mathrm{~mol} \mathrm{~s}^{-1} \mathrm{~m}^{-2}\left(u_{\mathrm{g}}^{0}\right.$ $\left.\approx 0.05 \mathrm{~m} \mathrm{~s}^{-1}\right)$, and the feed was undiluted with a stoichiometric composition $\left(\mathrm{H}_{2} / \mathrm{CO}_{2}=4\right)$. The temperature of the cooled wall $T_{\mathrm{w}}$ was set equal to the inlet gas temperature $T_{0}$.

5.1. Reactor Efficiency and Losses. For this set of simulations, the $\mathrm{CO}_{2}$ conversion at the reactor outlet was fixed at $66 \%$. The maximum temperature inside the reactor was fixed at $623 \mathrm{~K}$. This temperature yields high reaction rates and is of practical relevance while at the same time being low enough to help limit catalyst damage. The equilibrium is also favorable under these conditions since at $623 \mathrm{~K}$ and $1000 \mathrm{kPa}$, the equilibrium $\mathrm{CO}_{2}$ conversion is $96 \%$ and the selectivity toward $\mathrm{CH}_{4}$ is higher than $99 \%$. Thus, the kinetic regime is ensured, where chemical equilibrium does not significantly interfere with the obtained simulation results.

To reach the desired conversion and maximum temperature, the reactor length and the inlet temperature were varied. Three different tube diameters were simulated, $0.01,0.02$, and 0.025 $\mathrm{m}$, which are realistic dimensions for one individual tube inside a multitubular reactor, usually applied at a technical scale. $^{40,42,61}$

Figures 4-6 show the results of the performed simulations for different values of relative activity. The productivity is calculated as the hourly $\mathrm{CH}_{4}$ molar flow per reactor bed volume. This parameter was preferred for comparisons over the production because the amount of catalyst changes for

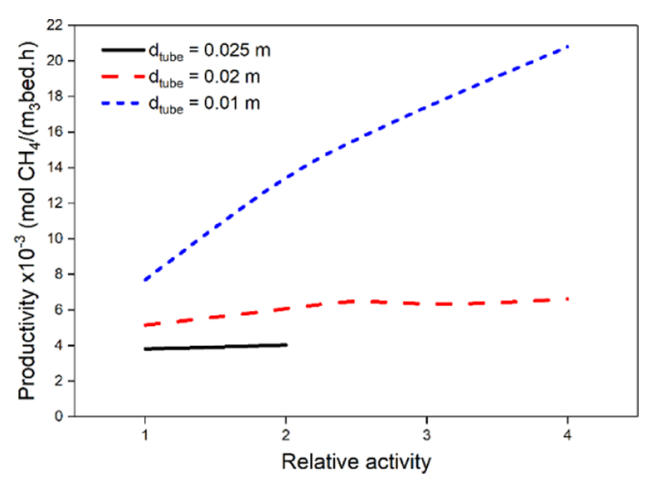

Figure 4. Productivity of different tube diameters as a function of the relative activity. different simulations. The productivity grows as the activity factor increases for all of the tube diameters (Figure 4). A proportional increment is expected for a differential reactor, but the high conversions and necessary reactor lengths result in an integral reactor behavior for these simulations, so the deviations from linearity are due to axial concentration and temperature gradients. The growth in productivity is more pronounced for the tube diameter of $0.01 \mathrm{~m}$. When duplicating the relative activity from 1 to 2 , the productivity grows $77 \%$, while it only grows $17 \%$ for the $0.02 \mathrm{~m}$ diameter tube. When duplicating the relative activity from 2 to 4 , the growth is 52 and $10 \%$, respectively. For the $0.025 \mathrm{~m}$ diameter tube, duplicating the relative activity from 1 to 2 yields a productivity increase of only $6 \%$. This comparison indicates that the higher activity of the catalyst is better utilized with the smaller diameter tube. The reason for the lower utilization for the larger diameters is the less efficient heat removal, which deviates the reactor operation temperatures from isothermal conditions. Larger tube diameters hinder the heat removal by increasing the distance for radial heat dispersion, as seen in eq 18 , and also impact the heat transfer near the wall by reducing the available surface area per unit of volume (eq 21).

For the $0.025 \mathrm{~m}$ diameter tube, and using values of relative activity higher than 2, the objective of reaching $66 \% \mathrm{CO}_{2}$ conversion while maintaining a maximum temperature of 623 $\mathrm{K}$ becomes unreachable from a practical perspective. The reactor operates in a region of parametric instability where the maximum temperature is very sensitive to small increases in $T_{0}$, and a thermal runaway can occur. The numerical solutions could not be found due to difficulties with numeric convergence. The same runaway behavior is observed for a $0.02 \mathrm{~m}$ diameter tube when the relative activity is increased beyond 4 . The occurrence of a thermal runaway derives from the strong radial heat transfer limitations, which translate into poor reaction heat removal and reactor cooling.

Figure 5 shows the reactor efficiency and efficiency losses calculated with eqs $26-29$. It is clear that the $0.01 \mathrm{~m}$ diameter

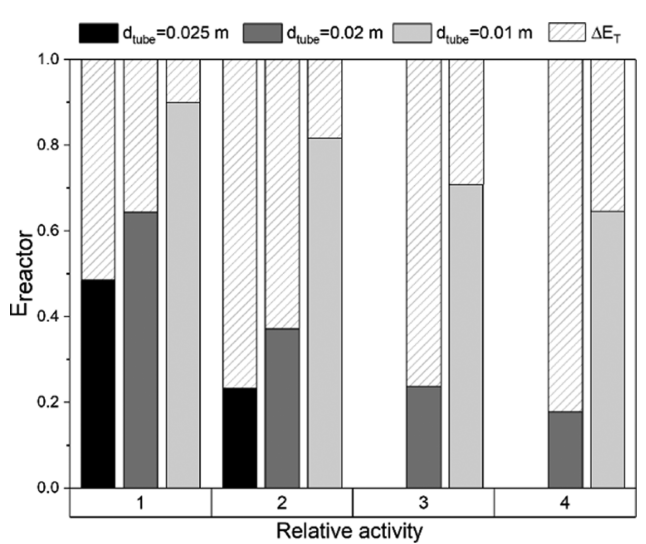

Figure 5. Efficiency and efficiency losses for different relative activities and tube diameters; the values of the efficiency losses due to internal and external mass transfer $\left(\Delta E_{\text {int }}, \Delta E_{\text {ext }}\right)$ are in the order of magnitude of $10^{-7}$ and can be considered negligible.

tube shows the highest values of efficiency for all relative activities, which is consistent with the higher productivities achieved since the catalyst bed is better utilized. While the efficiency decreases as the intrinsic activity increases, the drop is more pronounced for the larger diameters, reaching quite low values for higher relative activities. The $0.02 \mathrm{~m}$ diameter 
tube yields an efficiency value of 0.38 for the relative activity of 2 , while the $0.025 \mathrm{~m}$ diameter tube shows an efficiency value of 0.23 for the same activity.

Since the inlet molar flow rate per cross-sectional area stays constant through all simulations, negligible variations of external mass transfer are expected due to changes in tube diameter. The Sherwood number for these simulations is around 0.36 , which is quite a small value, due to the low gas velocities used in this study and small fiber diameter. However, such a small fiber diameter gives a large external surface area. The external mass transfer is enhanced this way, fast enough that there is no significant difference in concentrations at the catalyst surface and gas bulk, and the efficiency losses are insignificant.

The internal mass transfer limitations might register variations between different tube diameters, due to the increases in reaction rates at elevated temperatures. However, this does not have a big impact on the efficiency because of the thin catalyst layer, which is $0.4 \mu \mathrm{m}$ in thickness. The internal limitations are very small, due to such a small diffusion length. In fact, with the highest relative activity 4 , and the $0.025 \mathrm{~m}$ diameter tube, the efficiency loss due to diffusional effects is in the order of $1 \times 10^{-6}$.

It is evident that heat transfer limitations are the main cause of the efficiency losses and strongly depend on the diameter of the tube. Since the temperatures of the solid and gas phase resulted in practically identical values along the reactor for all simulations $\left(T_{\mathrm{s}}=T_{\mathrm{g}}=T\right)$, there are no relevant gas-solid heat transfer limitations. This is due to the high external surface area of the fibers, similar to the external mass transfer, even though the Nusselt number is in the lower range $(N u \approx 0.15)$. The main efficiency losses thus come from the limited radial heat removal from the catalyst bed toward the cooling medium. The larger tube diameters develop a more pronounced temperature profile along the axial direction, due to the lower specific surface area for heat removal (see Figure S1 in the Supporting Information). In turn, the inlet and cooling temperature needs to be lower to keep the $T_{\max }$ at 623 $\mathrm{K}$. The consequences on the reaction rates, which are the basis for efficiency analysis, are as follows. The reaction rates and thus the release of reaction heat increase quickly following the reactor inlet first, due to high reactant concentrations and rising temperature. The rising temperature also increases the driving force for radial heat transfer, since the wall temperature is assumed as constant. Since the kinetics are quite sensitive to the $\mathrm{H}_{2}$ partial pressure, the reaction rates decrease as the conversion increases, which is overcompensated by temperature rise prior to reaching the temperature maximum in the reactor. At the maximum temperature, heat production by reaction equals heat removal. In the following, heat production decreases by decreasing reactant concentrations and thus reaction rates. Radial heat removal exceeds heat production and thus the reactor temperature approaches $T_{0}$, due to efficient cooling. A steeper temperature profile is thus responsible for a steeper reaction rate profile for larger diameters, which eventually leads to smaller average values und hence lower efficiency. In other words, the increasing deviation from isothermal operation at maximum temperature is responsible for the decreasing efficiency.

To reach the desired conversion, the reactor length might even increase due to the lower average reaction rates, which further reduces the productivity per reactor volume. For a relative activity of 2 , for example, the necessary reactor lengths (from larger to smaller tube diameter) are 1.26, 0.73, and 0.34 $\mathrm{m}$. Such increases in the reactor length also cause higher pressure drops (Figure 6). The pressure drop decreases as the

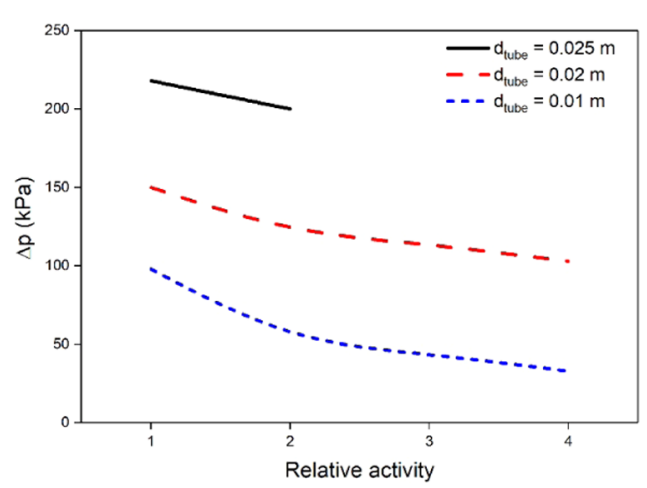

Figure 6. Total pressure drop for different tube diameters as a function of the relative activity.

intrinsic activity increases for all cases because the needed reactor length diminishes. However, the higher rate of heat generation following the reactor inlet provokes an even steeper temperature profile, leading to smaller average reaction rates. This tends to increase the reactor length, compensating for the increase in the intrinsic activity and causing the pressure drop curve to flatten at higher values of relative activity.

From the previously discussed points, it is clear that the factors that greatly influence the efficiency and performance of a reactor packed with a ceramic paper catalyst are the reaction heat removal through radial heat transfer and the pressure drop. The pressure drop has a direct economic impact, as it increases the operation and infrastructure costs. It can be reduced by modifying characteristics from the catalytic ceramic papers, namely, fiber diameter and bed porosity, which would require changing the starting materials and synthesis method. The heat transfer characteristics are further studied in this work in the following sections.

It is noteworthy that, in the performed simulations, the most relevant contribution to the effective radial thermal dispersion of the bed $\lambda_{\text {eff }}$ is the static contribution $\lambda_{0}$ (eqs 19 and 20). This is due to the low gas velocities that have been used and the small fiber diameters, which play into the Péclet number $\left(P e_{\mathrm{T}}\right)$ for the dynamic contribution. In fact, the dynamic term from eq 19 represents less than $1 \%$ of $\lambda_{\text {eff. }}$ At the same time, the heat transfer resistance near the wall $\left(h_{\mathrm{w}}^{-1}\right)$, which is strongly influenced by gas velocity through the Reynolds number, accounts for less than $10 \%$ of the total heat transfer resistance $h_{\text {eff }}^{-1}$. Consequently, increasing the gas velocity for improved heat transfer will hardly be effective, in particular, when considering the associated increase in pressure drop, which can become prohibitive. Larger fiber diameters, in contrast, would both increase the Péclet number and reduce the pressure drop from the Ergun equation, while the specific surface area for interfacial heat and mass transfer decreases. A promising approach would be combining fiber materials with higher thermal conductivity (such as $\mathrm{SiC}$ ) to increase the static contribution to radial heat dispersion and a sufficiently larger fiber diameter to reduce pressure drop while maintaining fast rates of heat and mass transfer.

5.2. Sensitivity Analysis: Heat Transfer toward the Cooled Wall. The effect of inlet temperature $T_{0}$ on the maximum temperature developed inside the reactor, as well as 

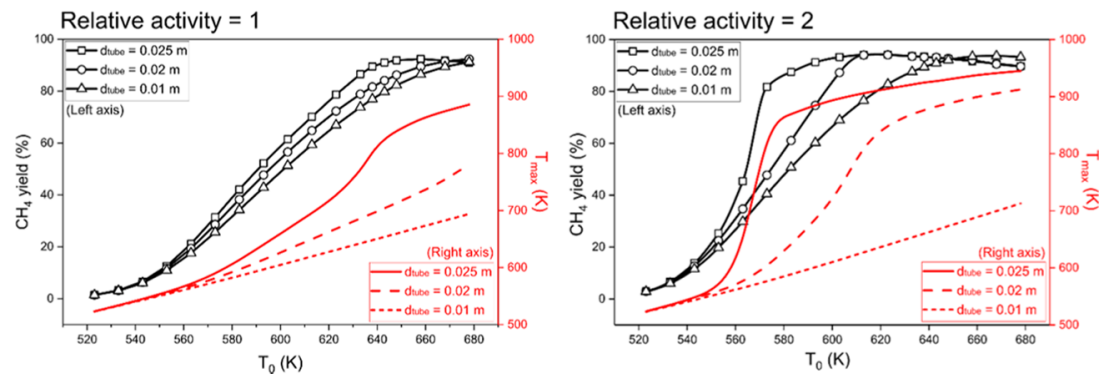

Figure 7. $\mathrm{CH}_{4}$ yield and maximum temperature as a function of the inlet temperature for different tube diameters and relative activity.

the achievable $\mathrm{CH}_{4}$ yield, was studied for a fixed reactor length of $0.5 \mathrm{~m}$ and two different values of relative activity (Figure 7). For a relative activity of 1 , it can be seen that the $\mathrm{CH}_{4}$ yield curves are quite close together for the three different diameters, so that the yield obtained for the same inlet temperature is similar, especially at lower values of $T_{0}$. The temperature at the hotspot is evidently higher for the larger tube diameters due to lower radial heat removal rates, although relatively high yields ( $\approx 60 \%)$ can be achieved with moderate temperatures (below $700 \mathrm{~K})$ for all tube diameters.

For a relative activity of 2 , the $\mathrm{CH}_{4}$ yield and $T_{\max }$ profiles grow more abruptly. In particular, for the 0.025 diameter tube, a region of parametric sensitivity appears in the range of relatively low inlet temperatures between 553 and $583 \mathrm{~K}$. This temperature range can be studied through the Semenov number $(\mathrm{Se})$ from eq 33, which represents the ratio of heat production rate to cooling rate and characterizes the temperature profile inside the reactor. ${ }^{62}$ Small values $(\mathrm{Se} \rightarrow$ 0 ) represent reactors with isothermal behavior, while very high values $(\mathrm{Se} \rightarrow \infty)$ represent adiabatic behavior.

$$
S e=-\frac{d_{\text {tube }}}{4 h_{\mathrm{eff}, 0}} \frac{\rho_{\mathrm{cat}} r_{\mathrm{eff}, 0} \Delta H_{\mathrm{r}, 0}}{T_{0}} \frac{E_{\mathrm{a}}}{R T_{0}}
$$

The Semenov number for $d_{\text {tube }}=0.025 \mathrm{~m}$ grows from 1.9 (at $553 \mathrm{~K}$ ) to 8.1 (at $583 \mathrm{~K}$ ), representing the reactor profile deviating from an isothermal operation, since the hotspot temperature grows quickly to high values. Adiabatic temperature profiles are not reached, however, because quite high conversions are reached around the hotspot, so the reaction slows down, and the reactor is quickly cooled following the maximum in temperature. The regions of high sensitivity have to be avoided nonetheless for safe reactor operation, and thus the inlet temperature is limited to below 550 or above $580 \mathrm{~K}$ for the $0.025 \mathrm{~m}$ diameter tube. The lower inlet temperature results in low $\mathrm{CH}_{4}$ yields along with a moderate hotspot, while for higher inlet temperatures above $650 \mathrm{~K}$ equilibrium constraints can be observed limiting the $\mathrm{CH}_{4}$ yield to $85 \%$ or less for the 0.025 and $0.02 \mathrm{~m}$ diameter tubes. Apart from this, high temperatures also favor catalyst deactivation by thermal degradation and sintering of the $\mathrm{Ni}$ nanoparticles and are thus not favorable.

In contrast, the tube diameter of $0.01 \mathrm{~m}$ has a moderate slope for $T_{\max }$ because the heat removal is very efficient. The Semenov number lies between 0.3 and 1.3 in the temperature range from 553 to $583 \mathrm{~K}$, indicating a reactor behavior closer to being isothermal. With this tube diameter, yields of $90 \%$ and above can be achieved with higher $T_{0}$ and hotspots lower than $700 \mathrm{~K}$.

A set of simulations with variation of the parameter $b$ (see eq 20) was performed to evaluate the impact of the accuracy of the used correlations, which are originally formulated for ceramic sponges. The parameter weighs the ratio of parallel to serial heat transfer and thus relates to the degree of continuity of the solid phase. In the case of a ceramic paper, the solid phase is likely to have a lower degree of continuity than a ceramic sponge, which would mean that the parameter $b$ would be either equal to or higher than that of a ceramic sponge. In other words, radial heat transport by conduction in the solid phase is less pronounced compared to that in sponges, while it is primarily characterized by sequential gas-solid heat transfer and conduction in the gas phase.

For sensitivity analysis, a relative activity of 1 and a tube diameter of $0.025 \mathrm{~m}$ were used, with the maximum temperature fixed at $623 \mathrm{~K}$. The reactor length was left as a free variable to meet a $\mathrm{CO}_{2}$ conversion of $66 \%$. Figure 8 shows

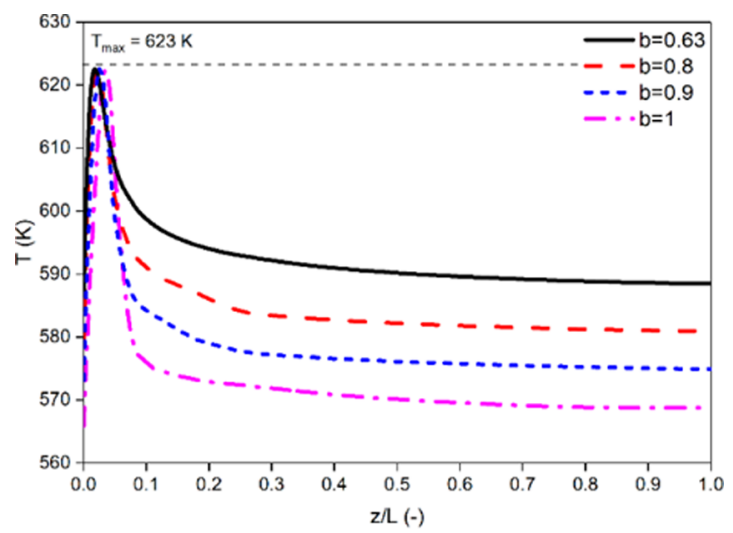

Figure 8. Temperature profiles along the reactor for a relative activity of 1 and different values of $b$, with the maximum temperature fixed at $623 \mathrm{~K}$.

the temperature profiles obtained for different values of $b$. Since the heat conduction in the continuous solid exceeds that of a sequential heat transfer scheme, heat removal is hindered with increasing parameter $b$, which requires a lower inlet temperature to meet the desired hotspot temperature. As discussed above, the average reaction rate becomes lower and a longer reactor is needed to achieve the desired conversion (reactor lengths from Figure 8 are, from lower to higher values of $b, 1.40,1.60,1.79$, and $1.95 \mathrm{~m}$ ). It is evident that the higher the parameter $b$, the lower the efficiency of the reactor, which originates from the low $T_{0}$. A parameter $b$ equal to 1 is the more extreme case, in which all of the heat transfer happens in series. Although the ceramic paper is not a continuous phase as sponges are, there are many contact points between the fibers, joined by alumina binder. Also, it is likely that there are more contributions to heat transfer due to radial mixing and 
turbulence, due to the small size of the fibers compared to sponge struts. Therefore, it is unlikely that the parameter $b$ measured for ceramic papers would result close to 1 . Presumably, no large error would be committed if the parameter $b$ is assumed to be between 0.63 and 0.8 for a ceramic paper catalyst. The efficiency for these two values of $b$ is 0.51 and 0.45 , respectively, which does not represent a significant change. However, a specific study for heat transfer in ceramic papers would be needed to affront these questions more accurately.

Figure 9 shows the development of the hotspot temperature and $\mathrm{CH}_{4}$ yield as a function of the inlet temperature for
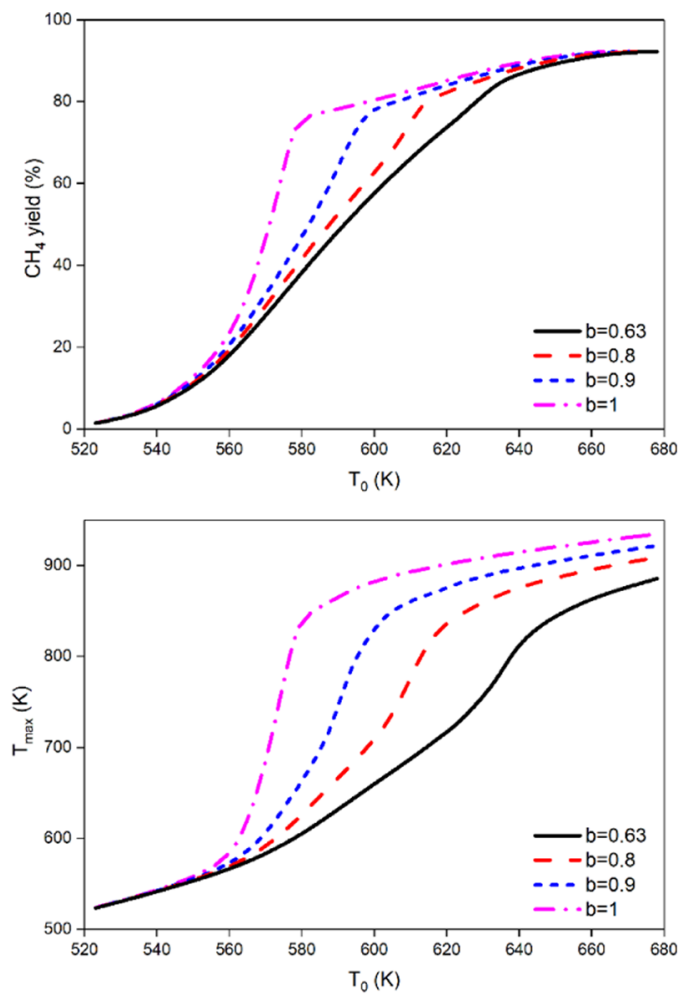

Figure 9. $\mathrm{CH}_{4}$ yield and maximum temperature as functions of the inlet temperature for a relative activity of 1 and different values of $b$.

different values of $b$ and a reactor length of $0.5 \mathrm{~m}$. The tube diameter used was $0.025 \mathrm{~m}$. The higher values of $b$ exhibit a higher parametric sensitivity, since the radial heat removal becomes more restricted, which becomes rather obvious from the maximum temperature graph. At the highest values of $T_{0}$, even the reactor with the better heat transfer $(b=0.63)$ reaches hotspot temperatures of above $850 \mathrm{~K}$, which are detrimental to catalyst stability. This is due to the inefficient heat transfer for the tube diameter of $0.025 \mathrm{~m}$, as already discussed. Along with the increasing maximum temperature, the $\mathrm{CH}_{4}$ yield also increases at lower $T_{0}$ as $b$ increases. At the highest inlet temperatures, all of the reactors reach high values of $\mathrm{CH}_{4}$ yield close to equilibrium, which is around $93.7 \%$ at $673 \mathrm{~K}$. However, only for values of $b$ of 0.63 and 0.8 relatively high yields $(\approx 60 \%)$ can be reached while maintaining moderate hotspot temperatures below $700 \mathrm{~K}$. With an inlet temperature of $598 \mathrm{~K}$, the values of $S e$ for $b=0.63$ and 0.8 are 6.6 and 8.8, respectively, indicating similar temperature profiles. In this line, it again seems reasonable to consider values of $b$ between 0.63 and 0.8 for ceramic papers, as previously discussed.

For all simulations performed with different values of $b$, the hotspot appears in the first $10 \mathrm{~cm}$ of the reactor, followed by the cooling, which has the temperature approaching $T_{0}$ rather quickly. The nature of such temperature profiles suggests the need for different strategies that aim at distributing the heat production more uniformly along the catalytic bed.

\section{CONCLUSIONS}

Ceramic paper catalysts containing $\mathrm{Ni}$ were studied using $\mathrm{CO}_{2}$ methanation as a test reaction. Experimental data was successfully fitted with a model, and simulations were performed to investigate the mass and heat transfer behavior of these materials and the effect on the reactor efficiency. In addition, a sensitivity analysis was carried out focusing on heat transfer towards the wall.

The small fiber diameter provides a high external surface area, allowing for efficient external mass and heat transfer even at the low gas velocities that were used in this study. Internal mass transfer resistance is not relevant due to the small diffusion lengths, even when increasing the intrinsic activity several times.

The heat transfer toward the wall is the primary resistance reducing the efficiency of the reactor, mainly due to poor radial heat dispersion, which is ultimately related to catalyst bed conductivity. Although increasing the gas flow can help enhance the heat transfer near the wall, the pressure drop would quickly become prohibitive due to the small fiber diameter. Changes in the material synthesis would help overcome these limitations. Fibers made of materials with higher thermal conductivity would be desirable to improve the radial heat dispersion, which would also allow to incorporate higher amounts of the active material onto the fibers. Besides that, fibers of larger diameters could be useful to increase gas flow with a lower pressure drop, but a compromise should be found with the reduction in external mass and heat transfer area.

An interesting perspective comes from the flexibility in the arrangement of the material that ceramic papers offer. Since the simulations show that the maximum reaction rates and temperatures are situated close to the reactor inlet, stacking layers of ceramic paper with increasing metal loadings along the reactor might be a suitable strategy to optimize the temperature profiles and work as close as possible to the maximum allowable temperatures.

\section{ASSOCIATED CONTENT}

\section{SI Supporting Information}

The Supporting Information is available free of charge at https://pubs.acs.org/doi/10.1021/acs.iecr.0c01997.

Inlet and outlet compositions and $\mathrm{CO}_{2}$ conversion and methane selectivity for the performed experiments (Table S1); summary of the parameters used for the simulations (Table S2); temperature profiles for three different tube diameters and relative activity of 1 ; maximum temperature fixed at $623 \mathrm{~K}$ and $\mathrm{CO}_{2}$ conversion at $66 \%$; inlet temperature adjusted accordingly (Figure S1) (PDF) 


\section{AUTHOR INFORMATION}

\section{Corresponding Author}

Robert Güttel - Institute of Chemical Engineering, Ulm

University, 89081 Ulm, Germany; ๑ orcid.org/0000-0002-

9709-1388; Email: robert.guettel@uni-ulm.de

\section{Authors}

Agustina Sánchez - Instituto de Investigaciones en Catálisis y Petroquímica, INCAPE (FIQ, UNL-CONICET), 3000 Santa

$\mathrm{Fe}$, Argentina; Institute of Chemical Engineering, Ulm University, $89081 \mathrm{Ulm}$, Germany

Viviana G. Milt - Instituto de Investigaciones en Catálisis y Petroquímica, INCAPE (FIQ, UNL-CONICET), 3000 Santa $\mathrm{Fe}$, Argentina

Eduardo E. Miró - Instituto de Investigaciones en Catálisis y Petroquímica, INCAPE (FIQ, UNL-CONICET), 3000 Santa Fe, Argentina; $\odot$ orcid.org/0000-0002-1381-7621

Complete contact information is available at:

https://pubs.acs.org/10.1021/acs.iecr.0c01997

\section{Author Contributions}

The manuscript was written through the contributions of all authors. All authors have given approval to the final version of the manuscript.

\section{Notes}

The authors declare no competing financial interest.

\section{ACKNOWLEDGMENTS}

The authors acknowledge the financial support received from Agencia Nacional de Promoción Científica y Tecnológica (ANPCyT, grant PICT 2016 no. 2710), Consejo Nacional de Investigaciones Científicas y Técnicas (CONICET, grant PIP 2015), and Deutscher Akademischer Austauschdienst (DAAD, CUAA-DAHZ, grant D/14/07554). The authors also thank Luis Lugo España for his help with the experimental work.

\section{NOTATION}

\section{Latin Letters}

$a_{\mathrm{f}}(1)$

$a_{\mathrm{gs}}\left(\mathrm{m}^{-1}\right)$

$b(1)$

$c\left(\mathrm{~mol} \mathrm{~m}^{-3}\right)$

$c_{\mathrm{p}}\left(\mathrm{kJ} \mathrm{mol}^{-1} \mathrm{~K}^{-1}\right)$

$d(\mathrm{~m})$

$D\left(\mathrm{~m}^{2} \mathrm{~s}^{-1}\right)$

E (1)

$E_{\mathrm{a}}\left(\mathrm{kJ} \mathrm{mol}^{-1}\right)$

$h\left(\mathrm{~kW} \mathrm{~m}{ }^{-2} \mathrm{~K}^{-1}\right)$

$\mathrm{Hg}$ (1)

$\Delta H_{\mathrm{r}}\left(\mathrm{kJ} \mathrm{mol}{ }^{-1}\right)$

$k_{\mathrm{gs}}\left(\mathrm{m} \mathrm{s}^{-1}\right)$

$K_{j}$

$k_{j}$

$M\left(\mathrm{~kg} \mathrm{~mol}^{-1}\right)$

$\mathrm{Nu}$ (1) activity factor for scaling the reaction kinetics gas-solid surface area per bed volume parallel to serial heat transfer parameter from eq ${ }^{20}$

concentration

heat capacity

diameter

diffusion coefficient

efficiency

activation energy

heat transfer coefficient

Hagen number, $H g=\frac{\rho(\Delta p / \Delta z) d^{3}}{\mu^{2}}$

reaction enthalpy

gas-solid mass transfer coefficient

adsorption constant of species $i$, units from ref 49

equilibrium constant of reaction $j$, units from ref 49

reaction rate constant for reaction $j$, units from ref 49

molecular weight

Nusselt number, $N u=\frac{h d}{\lambda}$

\begin{tabular}{|c|c|}
\hline$p(\mathrm{kPa})$ & pressure \\
\hline & Péclet number, $P e=\frac{u d}{D}$ \\
\hline$P e_{\mathrm{T}}(1)$ & thermal Péclet number, \\
\hline $\begin{array}{l}\Delta p(\mathrm{kPa}) \\
p_{\mathrm{i}}(\mathrm{kPa})\end{array}$ & $\begin{array}{l}P e=\operatorname{RePr}=\frac{d u \rho c_{\mathrm{p}}}{\lambda} \\
\text { pressure drop } \\
\text { partial pressure }\end{array}$ \\
\hline & Prandtl number, $\operatorname{Pr}=\stackrel{c_{1}}{-}$ \\
\hline$r\left(\mathrm{~mol} \mathrm{~kg}{ }_{\mathrm{cat}}^{-1} \mathrm{~s}^{-1}\right)$ & reaction rate \\
\hline$R\left(\mathrm{~kJ} \mathrm{~mol}^{-1} \mathrm{~K}^{-1}\right)$ & universal gas constant \\
\hline & Reynolds number, $R e=$ \\
\hline$S c(1)$ & Schmidt number, $S c=$ \\
\hline $\operatorname{Se}(1)$ & Semenov number, \\
\hline $\operatorname{Sh}(1)$ & $\begin{array}{l}S e=-\frac{d_{\text {tube }}}{4 h_{\text {eff }, 0}} \frac{\rho_{\text {at }}}{r_{\text {eff }, 0} \Delta H_{\mathrm{r}, 0}} \frac{E_{\mathrm{a}}}{R T} \\
\text { Sherwood number, } S h=\end{array}$ \\
\hline $\begin{array}{l}S_{\mathrm{v}}\left(\mathrm{m}^{-1}\right) \\
T(\mathrm{~K}) \\
u\left(\mathrm{~m} \mathrm{~s}^{-1}\right) \\
x(1) \\
x_{\mathrm{f}}(\mathrm{m}) \\
y(\mathrm{~m}) \\
z(\mathrm{~m})\end{array}$ & $\begin{array}{l}\text { external surface area } \\
\text { temperature } \\
\text { superficial velocity } \\
\text { molar fraction } \\
\text { mixing length for cerami } \\
\text { internal coordinate insid } \\
\text { axial coordinate }\end{array}$ \\
\hline \multicolumn{2}{|c|}{ G GREK LETTERS } \\
\hline $\begin{array}{ll}\delta(\mathrm{m}) & 1 \\
\varepsilon(1) & \\
\eta(1) & \\
\lambda\left(\mathrm{kW} \mathrm{m}^{-1} \mathrm{~K}^{-1}\right) & \mathrm{t} \\
\mu(\mathrm{kPa} \mathrm{s}) & \\
\nu(1) & \mathrm{t} \\
\rho\left(\mathrm{kg} \mathrm{m}^{-3}\right) & \\
\tau(1) & \mathrm{t}\end{array}$ & $\begin{array}{l}\text { layer thickness } \\
\text { porosity } \\
\text { effectiveness factor } \\
\text { thermal conductivity } \\
\text { viscosity } \\
\text { stoichiometric coefficient } \\
\text { density } \\
\text { tortuosity }\end{array}$ \\
\hline
\end{tabular}

\section{SUBSCRIPTS}

0 reactor inlet

cat catalyst

eff effective

f fiber

g gas

gs gas-solid

$\mathrm{h}$ hydraulic

K Knudsen

$\mathrm{m}$ molecular

max maximum

$\mathrm{p}$ pore

s solid

S Sauter

tube reactor tube

w wall

\section{REFERENCES}

(1) Wakao, N.; Smith, J. M. Diffusion and Reaction in Porous Catalysts. Ind. Eng. Chem. Fundam. 1964, 3, 123-127.

(2) Weisz, P. B.; Hicks, J. S. The Behaviour of Porous Catalyst Particles in View of Internal Mass and Heat Diffusion Effects. Chem. Eng. Sci. 1962, 17, 265-275.

(3) Eigenberger, G.; Ruppel, W. Catalytic Fixed-Bed Reactors. Ullmann's Encyclopedia of Industrial Chemistry; Wiley-VCH: Weinheim, 2012. 
(4) Schwartz, C. E.; Smith, J. M. Flow Distribution in Packed Beds. Ind. Eng. Chem. 1953, 45, 1209-1218.

(5) Andrigo, P.; Bagatin, R.; Pagani, G. Fixed Bed Reactors. Catal. Today 1999, 52, 197-221.

(6) Kreutzer, M. T.; Kapteijn, F.; Moulijn, J. A. Shouldn't Catalysts Shape up? Structured Reactors in General and Gas-Liquid Monolith Reactors in Particular. Catal. Today 2006, 111, 111-118.

(7) Güttel, R.; Turek, T. Improvement of Fischer-Tropsch Synthesis through Structuring on Different Scales. Energy Technol. 2016, 4, 4454.

(8) Güttel, R. Structuring of Reactors and Catalysts on Multiple Scales: Potential and Limitations for Fischer-Tropsch Synthesis. Chem. Ing. Tech. 2015, 87, 694-701.

(9) Pangarkar, K.; Schildhauer, T. J.; van Ommen, J. R.; Nijenhuis, J.; Kapteijn, F.; Moulijn, J. A. Structured Packings for Multiphase Catalytic Reactors. Ind. Eng. Chem. Res. 2008, 47, 3720-3751.

(10) Roy, S.; Bauer, T.; Al-Dahhan, M.; Lehner, P.; Turek, T. Monoliths as Multiphase Reactors: A Review. AIChE J. 2004, 50, 2918-2938.

(11) Cybulski, A.; Moulin, J. Monoliths in Heterogeneous Catalysis. Catal. Rev. 1994, 36, 179-270.

(12) Giani, L.; Groppi, G.; Tronconi, E. Mass-Transfer Characterization of Metallic Foams as Supports for Structured Catalysts. Ind. Eng. Chem. Res. 2005, 44, 4993-5002.

(13) Twigg, M. V.; Richardson, J. T. Fundamentals and Applications of Structured Ceramic Foam Catalysts. Ind. Eng. Chem. Res. 2007, 46, $4166-4177$.

(14) Reichelt, E.; Heddrich, M. P.; Jahn, M.; Michaelis, A. Fiber Based Structured Materials for Catalytic Applications. Appl. Catal., A 2014, 476, 78-90.

(15) Bortolozzi, J. P.; Banús, E. D.; Milt, V. G.; Miro, E. E. New Formulations of Ni-Containing Ceramic Papers to Enhance the Catalytic Performance for the Oxidative Dehydrogenation of Ethane. Ind. Eng. Chem. Res. 2014, 53, 17570-17579.

(16) Matatov-Meytal, Y.; Sheintuch, M. Catalytic Fibers and Cloths. Appl. Catal., A 2002, 231, 1-16.

(17) Cuo, Z.; Deng, Y.; Li, W.; Peng, S.; Zhao, F.; Liu, H.; Chen, Y. Monolithic Mn/Ce-Based Catalyst of Fibrous Ceramic Membrane for Complete Oxidation of Benzene. Appl. Surf. Sci. 2018, 456, 594-601.

(18) Wang, Z.; Cheng, Y.; Shao, X.; Veder, J. P.; Hu, X.; Ma, Y.; Wang, J.; Xie, K.; Dong, D.; Ping Jiang, S.; Parkinson, G.; Buckley, C.; Li, C. Z. Nanocatalysts Anchored on Nanofiber Support for High Syngas Production via Methane Partial Oxidation. Appl. Catal., A 2018, 565, 119-126.

(19) Ma, Y.; Ma, Y.; Zhao, Z.; Hu, X.; Ye, Z.; Yao, J.; Buckley, C. E.; Dong, D. Comparison of Fibrous Catalysts and Monolithic Catalysts for Catalytic Methane Partial Oxidation. Renewable Energy 2019, 138, 1010-1017.

(20) Danaci, S.; Protasova, L.; Snijkers, F.; Bouwen, W.; Bengaouer, A.; Marty, P. Innovative 3D-Manufacture of Structured Copper Supports Post-Coated with Catalytic Material for $\mathrm{CO}_{2}$ Methanation. Chem. Eng. Process. Process Intensif. 2018, 127, 168-177.

(21) Middelkoop, V.; Vamvakeros, A.; De Wit, D.; Jacques, S. D. M.; Danaci, S.; Jacquot, C.; De Vos, Y.; Matras, D.; Price, S. W. T.; Beale, A. M. 3D Printed Ni/ $/ \mathrm{Al}_{2} \mathrm{O}_{3}$ Based Catalysts for $\mathrm{CO}_{2}$ Methanation-a Comparative and Operando XRD-CT Study. J. $\mathrm{CO}_{2}$ Util. 2019, 33, $478-487$.

(22) Leonardi, S. A.; Zanuttini, M. A.; Miró, E. E.; Milt, V. G. Catalytic Paper Made from Ceramic Fibres and Natural Ulexite. Application to Diesel Particulate Removal. Chem. Eng. J. 2017, 317, 394-403.

(23) Cecchini, J. P.; Banús, E. D.; Leonardi, S. A.; Zanuttini, M. A.; Ulla, M. A.; Milt, V. G. Flexible-Structured Systems Made of Ceramic Fibers Containing Pt-NaY Zeolite Used as CO Oxidation Catalysts. J. Mater. Sci. 2015, 50, 755-768.

(24) Bortolozzi, J. P.; Banús, E. D.; Terzaghi, D.; Gutierrez, L. B.; Milt, V. G.; Ulla, M. A. Novel Catalytic Ceramic Papers Applied to Oxidative Dehydrogenation of Ethane. Catal. Today 2013, 216, 2429.
(25) Tuler, F. E.; Gaigneaux, E. M.; Miró, E. E.; Milt, V. G.; Debecker, D. P. Catalytic Ceramic Papers for Diesel Soot Oxidation: A Spray Method for Enhanced Performance. Catal. Commun. 2015, $72,116-120$

(26) Tuler, F. E.; Banús, E. D.; Zanuttini, M. A.; Miró, E. E.; Milt, V. G. Ceramic Papers as Flexible Structures for the Development of Novel Diesel Soot Combustion Catalysts. Chem. Eng. J. 2014, 246, 287-298.

(27) Saimura, A.; Shiratori, Y.; Kitaoka, T. Dual-Layered PaperStructured Catalysts for Sequential Desulfurization and MethaneSteam Reforming of Simulated Biogas Containing Hydrogen Sulfide. J. Mater. Sci. 2017, 52, 314-325.

(28) Ishihara, Y.; Kanomata, K.; Homma, T.; Kitaoka, T. MultilayerStacked Paper-Structured Catalysts for Microflow Suzuki-Miyaura Cross-Coupling Reaction. React. Kinet., Mech. Catal. 2017, 121, 523537.

(29) Satterfield, C. N.; Cortez, D. H. Mass Transfer Characteristics of Woven-Wire Screen Catalysts. Ind. Eng. Chem. Fundam. 1970, 9, 613-620.

(30) Sun, H.; Shu, Y.; Quan, X.; Chen, S.; Pang, B.; Liu, Z. Y. Experimental and Modeling Study of Selective Catalytic Reduction of $\mathrm{NO}_{x}$ with $\mathrm{NH}_{3}$ over Wire Mesh Honeycomb Catalysts. Chem. Eng. J. 2010, 165, 769-775.

(31) Groppi, G.; Tronconi, E.; Bozzano, G.; Dente, M. Experimental and Theoretical Study of Gas/Solid Mass Transfer in Metallic Filters as Supports for Micro-Structured Catalysts. Chem. Eng. Sci. 2010, 65, 392-397.

(32) Reichelt, E.; Jahn, M. Generalized Correlations for Mass Transfer and Pressure Drop in Fiber-Based Catalyst Supports. Chem. Eng. J. 2017, 325, 655-664.

(33) Wallenstein, M.; Kind, M.; Dietrich, B. Radial Two-Phase Thermal Conductivity and Wall Heat Transfer Coefficient of Ceramic Sponges - Experimental Results and Correlation. Int. J. Heat Mass Transfer 2014, 79, 486-495.

(34) Kołodziej, A.; Łojewska, J.; Jaroszyński, M.; Gancarczyk, A.; Jodłowski, P. Heat Transfer and Flow Resistance for Stacked Wire Gauzes: Experiments and Modelling. Int. J. Heat Fluid Flow 2012, 33, $101-108$

(35) Giani, L.; Groppi, G.; Tronconi, E. Heat Transfer Characterization of Metallic Foams. Ind. Eng. Chem. Res. 2005, 44, 9078-9085.

(36) Cybulski, A.; Moulijn, J. A. Structured Reactors, a Wealth of Opportunities. Novel Concepts in Catalysis and Chemical Reactors; Wiley-VCH: Weinheim, 2010; pp 189-209.

(37) Van Noyen, J.; De Wilde, A.; Schroeven, M.; Mullens, S.; Luyten, J. Ceramic Processing Techniques for Catalyst Design: Formation, Properties, and Catalytic Example of ZSM-5 on 3Dimensional Fiber Deposition Support Structures. Int. J. Appl. Ceram. Technol. 2012, 9, 902-910.

(38) Yuranov, I.; Kiwi-Minsker, L.; Renken, A. Structured Combustion Catalysts Based on Sintered Metal Fibre Filters. Appl. Catal., B 2003, 43, 217-227.

(39) Kiwi-Minsker, L.; Yuranov, I.; Slavinskaia, E.; Zaikovskii, V.; Renken, A. Pt and Pd Supported on Glass Fibers as Effective Combustion Catalysts. Catal. Today 2000, 59, 61-68.

(40) Rönsch, S.; Schneider, J.; Matthischke, S.; Schlüter, M.; Götz, M.; Lefebvre, J.; Prabhakaran, P.; Bajohr, S. Review on Methanation From Fundamentals to Current Projects. Fuel 2016, 166, 276-296.

(41) Lalinde, J. A. H.; Jiang, J. S.; Jai, G.; Kopyscinski, J. Preparation and Characterization of $\mathrm{Ni} / \mathrm{Al}_{2} \mathrm{O}_{3}$ Catalyst Coatings on FeCrAl-Loy Plates Used in a Catalytic Channel Reactor with in-Situ Spatial Profiling to Study $\mathrm{CO}_{2}$ Methanation. Chem. Eng. J. 2019, 357, 435446.

(42) Ghaib, K.; Nitz, K.; Ben-Fares, F.-Z. Chemical Methanation of $\mathrm{CO}_{2}$ : A Review. ChemBioEng Rev. 2016, 3, 266-275.

(43) Frontera, P.; Macario, A.; Ferraro, M.; Antonucci, P. L. Supported Catalysts for $\mathrm{CO}_{2}$ Methanation: A Review. Catalysts 2017, 7, No. 59. 
(44) Busca, G. Catalytic Materials Based on Silica and Alumina: Structural Features and Generation of Surface Acidity. Prog. Mater. Sci. 2019, 104, 215-249.

(45) Reichelt, E.; Jahn, M.; Lange, R. Derivation and Application of a Generalized Correlation for Mass Transfer in Packed Beds. Chem. Ing. Tech. 2017, 89, 390-400.

(46) Martin, H. In The Leveque-Analogy or How to Predict Heat and Mass Transfer from Fluid Friction, 4th International Conference on Heat Transfer, Fluid Mechanics and Thermodynamics, Cairo, 2005.

(47) Dietrich, B. Heat Transfer Coefficients for Solid Ceramic Sponges-Experimental Results and Correlation. Int. J. Heat Mass Transfer 2013, 61, 627-637.

(48) de Wasch, A. P.; Froment, G. F. Heat Transfer in Packed Beds. Chem. Eng. Sci. 1972, 27, 567-576.

(49) Xu, J.; Froment, G. F. Methane Steam Reforming, Methanation and Water-gas Shift: I. Intrinsic Kinetics. AIChE J. 1989, 35, 88-96.

(50) Güttel, R.; Turek, T. Comparison of Different Reactor Types for Low Temperature Fischer-Tropsch Synthesis: A Simulation Study. Chem. Eng. Sci. 2009, 64, 955-964.

(51) Hu, C. W.; Yao, J.; Yang, H. Q.; Chen, Y.; Tian, A. M. On the Inhomogeneity of Low Nickel Loading Methanation Catalyst. J. Catal. 1997, 166, 1-7.

(52) Abelló, S.; Berrueco, C.; Montané, D. High-Loaded NickelAlumina Catalyst for Direct $\mathrm{CO}_{2}$ Hydrogenation into Synthetic Natural Gas (SNG). Fuel 2013, 113, 598-609.

(53) Garbarino, G.; Bellotti, D.; Riani, P.; Magistri, L.; Busca, G. Methanation of Carbon Dioxide on $\mathrm{Ru} / \mathrm{Al}_{2} \mathrm{O}_{3}$ and $\mathrm{Ni} / \mathrm{Al}_{2} \mathrm{O}_{3}$ Catalysts at Atmospheric Pressure: Catalysts Activation, Behaviour and Stability. Int. J. Hydrogen Energy 2015, 40, 9171-9182.

(54) Garbarino, G.; Riani, P.; Magistri, L.; Busca, G. A Study of the Methanation of Carbon Dioxide on $\mathrm{Ni} / \mathrm{Al}_{2} \mathrm{O}_{3}$ Catalysts at Atmospheric Pressure. Int. J. Hydrogen Energy 2014, 39, 1155711565 .

(55) Le, T. A.; Kim, M. S.; Lee, S. H.; Kim, T. W.; Park, E. D. CO and $\mathrm{CO}_{2}$ Methanation over Supported Ni Catalysts. Catal. Today 2017, 293-294, 89-96.

(56) Le, T. A.; Kang, J. K.; Lee, S. H.; Park, E. D. $\mathrm{CO}$ and $\mathrm{CO}_{2}$ Methanation Over $\mathrm{Ni} / \gamma-\mathrm{Al}_{2} \mathrm{O}_{3}$ Prepared by Deposition-Precipitation Method. J. Nanosci. Nanotechnol. 2019, 19, 3252-3262.

(57) Türks, D.; Mena, H.; Armbruster, U.; Martin, A. Methanation of $\mathrm{CO}_{2}$ on $\mathrm{Ni} / \mathrm{Al}_{2} \mathrm{O}_{3}$ in a Structured Fixed-Bed Reactor-A Scale-up Study. Catalysts 2017, 7, No. 152.

(58) Schlereth, D.; Hinrichsen, O. A Fixed-Bed Reactor Modeling Study on the Methanation of $\mathrm{CO}_{2}$. Chem. Eng. Res. Des. 2014, 92, $702-712$.

(59) Ducamp, J.; Bengaouer, A.; Baurens, P. Modelling and Experimental Validation of a $\mathrm{CO}_{2}$ Methanation Annular Cooled Fixed-Bed Reactor Exchanger. Can. J. Chem. Eng. 2017, 95, 241-252.

(60) Oliveira, E. L. G.; Grande, C. A.; Rodrigues, A. E. Steam Methane Reforming in a Ni/ $\mathrm{Al}_{2} \mathrm{O}_{3}$ Catalyst: Kinetics and Diffusional Limitations in Extrudates. Can. J. Chem. Eng. 2009, 87, 945-956.

(61) Ghaib, K.; Ben-Fares, F. Z. Power-to-Methane: A State-of-theArt Review. Renewable Sustainable Energy Rev. 2018, 81, 433-446.

(62) Kiewidt, L.; Thöming, J. Predicting Optimal Temperature Profiles in Single-Stage Fixed-Bed Reactors for $\mathrm{CO}_{2}$-Methanation. Chem. Eng. Sci. 2015, 132, 59-71. 